J. Linguistics 53 (2017), 567-611. C Cambridge University Press 2016

This is an Open Access article, distributed under the terms of the Creative Commons Attribution licence (http://creativecommons.org/licenses/by/4.0/), which permits unrestricted re-use, distribution, and reproduction in any medium, provided the original work is properly cited.

doi:10.1017/S0022226716000293 First published online 26 September 2016

\title{
Speakers' knowledge of alternations is asymmetrical: Evidence from Seoul Korean verb paradigms ${ }^{1}$
}

\author{
JONGHO JUN
}

Seoul National University

\author{
ADAM ALBRIGHT \\ Massachusetts Institute of Technology
}

(Received 1 October 2013; revised 24 June 2016)

This paper investigates whether and how speakers track the relative frequency of different patterns of alternation in the lexicon, by investigating speakers' behavior when they are faced with unpredictability in allomorph selection. We conducted a wug test on Seoul Korean verb paradigms, testing whether speakers can generalize reliable lexical patterns. The test was performed in two directions. In forward formation test, the pre-vocalic base and pre-consonantal non-base forms were the stimulus and response, respectively, whereas in backward formation test, the stimulus-response relation was switched. The results show patterns approximating statistical patterns in Seoul Korean verb lexicon, thus confirming the lexical frequency matching reported in many previous studies. However, contrary to the conventional assumption, the results of the backward formation test are consistent with lexical frequencies relevant for the forward formation, not backward formation. This observed asymmetry is broadly consistent with the single base hypothesis (Albright 2002a, b, 2005, 2008), in which forward, as opposed to backward formation rules play a privileged role in speakers' morphological grammar.

KEYWORDS: allomorph selection, alternation, Seoul Korean, single base hypothesis, wug test

[1] We would like to thank Edward Flemming, Michael Kenstowicz, Donca Steriade and the three anonymous Journal of Linguistics referees for their valuable suggestions and detailed comments. This paper has also benefited from comments and advice of many other people. We thank Lisa Davidson, Gillian Gallagher, Maria Gouskova, Sangjin Hwang, Shigeto Kawahara, Ju-won Kim, Heejeong Ko, Haruo Kubozono, Sang-Im Lee, Suyeon Yun, Kie Zuraw and audiences at Seoul National University, MIT, New York University and 7th Phonology Festa (Kyoto, Japan, February 2012) for their comments on earlier versions of this paper. We finally thank Hyewon Choi for supplying the data of the Standard Korean Dictionary, Seongkyu Kim for suggesting several useful references on Korean irregular alternations, Na-Young Park and Sangjin Hwang for their valuable assistance in experimental and corpus data collection, and our experimental participants for their time. This work was supported by the National Research Foundation of Korea Grant funded by the Korean Government (NRF-2011-013-A00019).

In the use of abbreviations, we follow the Leipzig Glossing Rules, with the addition of the following: HORT $=$ hortative, INT $=$ interrogative. 


\section{INTRODUCTION}

This paper aims to find out whether and how speakers track the relative frequency of different patterns of alternation in the lexicon, by investigating speakers' behavior when they are faced with unpredictability in allomorph selection. Unpredictability may arise when there is phonological neutralization in certain parts of the paradigm, and it may also arise in cases of exceptional (or 'irregular') processes. In both cases, the language contains some stems that alternate in a certain way within their paradigms, while other stems show different (or no) alternations, but this difference cannot be attributed to the phonological context. It is then unpredictable based on phonological properties of a stem whether and how it alternates. For instance, in Dutch, open syllable lengthening does not apply to all noun stems, e.g. [xat] [xa:.tən] 'hole, SG PL' but [kat] [ka.tən], not *[ka:. tən] 'cat, SG PL' (Coetzee 2008). Thus, if a speaker is faced with a new or unknown stem in the singular, it is not predictable whether the plural form has a lengthened vowel or not.

There are numerous theoretical devices for lexically encoding which stems undergo unpredictable alternations, such as attributing them to underlying phonological differences, marking certain stems as exceptions to phonological processes (Kenstowicz \& Kisseberth 1977, Pater 2000, Becker 2009), or lexically listing alternants (Pinker \& Prince 1988, Pinker 1999, Albright \& Hayes 2003, Zuraw 2010). However, lexical encoding/listing alone is not sufficient to explain speakers' knowledge of unpredictable alternations, since such processes often show some degree of productivity. Productivity shows that speakers have extrapolated knowledge that goes beyond the specific stems involved; speakers must also have grammatical rules or constraint rankings for exceptionful or irregular processes (Kenstowicz \& Kisseberth 1977; Zuraw 2000, 2010; Albright \& Hayes 2003; Hayes \& Londe 2006; Pater et al. 2012). Furthermore, it has been observed that in many cases, the productivity of an alternation reflects the relative frequency of that pattern in the lexicon. This is most directly captured by positing that grammars are probabilistic, and speakers apply rules (or constraint rankings) stochastically.

From this stochastic approach, some basic predictions can be made. First, when speakers must provide an inflected form of a novel stem, as in a wug test (Berko 1958), we expect that competing output forms should be generated with probabilities approximating the lexical frequencies of the relevant patterns. In addition, when speakers are asked to judge the acceptability of novel forms, they should have gradient well-formedness intuitions that correlate with statistical trends in the lexicon. This frequency matching prediction has been confirmed in numerous studies of unpredictable allomorphy, including Zuraw (2000, 2002, 2007, 2010), Albright, Andrade \& Hayes (2001), Bybee (2001), Albright (2002a, b), Albright \& Hayes (2003), Ernestus \& Baayen (2003), Hayes \& Londe (2006), Jun \& Lee (2007), Becker (2009), Jun (2010) and others.

It is thus clear that speakers have knowledge of at least some statistical lexical patterns. At the same time, there is evidence that speakers do not apply all processes as productively as their frequency in the lexicon would lead one to 
expect. This, too, is expected under a probabilistic grammatical approach, in which the probability of a rule or constraint ranking may be modulated by constraints on grammars and by prior expectations about likely processes or grammars. A number of recent studies on this issue focus on comparison between 'natural' vs. 'unnatural' patterns, testing whether speakers are less likely to generalize processes that have complex or phonetically unmotivated conditioning environments (Wilson 2006, Moreton 2008, Hayes et al. 2009, Becker, Ketrez \& Nevins 2011, Do 2013, Hayes \& White 2013, Jun 2015). In this study, we will focus on a different constraint, concerning the directionality of processes relating allomorphs. We test the single base hypothesis (Albright 2002a, 2005, 2008), according to which speakers identify a designated base form in the paradigm, and are constrained to learn rules that project other allomorphs based on this privileged base allomorph. In order to test this, we performed wug tests on Seoul Korean verbal paradigms. For reasons to be discussed in Section 1.1, we assume that the base form of Seoul Korean verbal paradigms is a pre-vocalic allomorph, found before a particular vowel-initial suffix. Adopting this assumption, we performed wug tests in two directions. In the forward formation test, speakers were presented with nonce verb stimuli in the pre-vocalic (pre-V) base form and were required to generate a pre-consonant (pre-C) non-base response, whereas in backward formation test, the stimulus-response relation was switched. The prediction is that responses in the forward (base $\rightarrow$ non-base) direction should accurately reflect statistical trends in the lexicon, whereas responses in the reverse (non-base $\rightarrow$ base) direction should not.

The results show that in the forward direction, speakers do indeed generalize patterns in a way that approximates the probability of different pre-vocalic to pre-consonantal (base $\rightarrow$ non-base) correspondences in the Seoul Korean verbal lexicon. This result confirms that speakers do have the capacity to match lexical frequencies, as reported in many previous studies. However, speakers' responses in the backward formation test do not correlate closely with the probability of pre-consonantal to pre-vocalic (non-base $\rightarrow$ base) correspondences. Instead, we will show that responses in the backward formation test are best modeled using probabilities of mappings in the FORWARD (base $\rightarrow$ non-base) direction. This asymmetry is predicted by the single base hypothesis (Albright 2002a, b, 2005, 2008), in which forward, as opposed to backward formation rules play a privileged role in speakers' morphological grammar.

The rest of this paper is organized as follows. In the remainder of this section, we provide background information about Seoul Korean verbal paradigms, presenting the probabilities of forward and backward formation rules for the alternation classes of Seoul Korean verbs, based on Albright \& Hayes's (2002, 2003) minimal generalization learner. We then discuss potential models of allomorph selection and their predictions for wug tests on Seoul Korean verbal paradigms. Section 2 describes the method and procedure of the experiments, and reports the results. In Section 3, we compare different models of the experimental results, and show that the results of the backward formation test are more consistent with the predictions of forward formation rules than those of backward formation 
rules. In Sections 4 and 5, we discuss alternative accounts and remaining puzzles. The final section concludes this study.

\subsection{Seoul Korean verbal paradigms}

Seoul Korean has a three-way laryngeal contrast between lenis, aspirated and tense (or glottalized) obstruents, as shown in Table 1.

\begin{tabular}{|c|c|c|c|c|c|}
\hline & Labial & \multicolumn{3}{|c|}{ Coronal } & Velar \\
\hline & Stop & Stop & Fricative & Affricate & Stop \\
\hline Lenis & $\mathrm{p}$ & $\mathrm{t}$ & $\mathrm{s}$ & c & $\mathrm{k}$ \\
\hline Aspirated & $\mathrm{p}^{\mathrm{h}}$ & $t^{\mathrm{h}}$ & & $c^{h}$ & $\mathrm{k}^{\mathrm{h}}$ \\
\hline Tense & p' & $t^{\prime}$ & s' & c' & $\mathrm{k}^{\prime}$ \\
\hline
\end{tabular}

Table 1

Three-way laryngeal distinction among obstruents in Korean.

All obstruents neutralize to their homorganic lenis stop counterparts in coda position: coronal stops, affricates and fricatives neutralize to [t], labial stops to [p] and velar stops to [k]. This coda neutralization process applies with no exception, often yielding stem-final alternations in the verbal paradigm, which will be illustrated shortly.

All verb forms in Korean are suffixed, and verb stems never occur in isolation. Verbal suffixes may be classified into the following four types, based on Choi (1985) and Kang (2006).

\section{(1) Four types of verbal suffix in Korean}

(a) V-initial suffix: -a/ə 'imperative' and many other meanings.

([a] if the stem-final vowel is [a,o]; otherwise, [ə].) $)^{2}$

(b) C-initial suffix: e.g. -ca 'hortative', -ko 'progressive'.

([i] is not inserted even when the stem ends in a consonant.)

(c) (i)C-initial suffix: e.g. -(i)mjən 'if'.

([i] is present only when the stem ends in a consonant other than [1].)

(d) (Ci)C-initial suffix: e.g. -(si)p 'addressee honorific'.

( $\mathrm{C} \dot{\mathrm{i}}$ is present only when the stem ends in a consonant.)

[2] When the stem-final vowel is [a], [ə] can also be adopted as a suffix-initial vowel, e.g. /mak/ 'block (IMP)' [maka] [makə]. Accordingly, suffix-initial [ə] can occur with all stems except those with final /o/ vowel. 
With respect to stem-final (non-)alternation, (i)C-initial and (Ci)C-initial suffixes behave like $\mathrm{V}$-initial and $\mathrm{C}$-initial suffixes, respectively, and thus we will focus on the latter two suffix types.

The process of coda neutralization creates unpredictable alternations in Seoul Korean verbal paradigms. Since stem-final obstruents are neutralized before $\mathrm{C}$-initial suffixes but remain distinct before V-initial suffixes, stems may exhibit allomorphy, as shown in (2).

(2) Some (non-)alternating verb classes: Pre-C forms are neutralized due to coda neutralization ${ }^{3,4}$

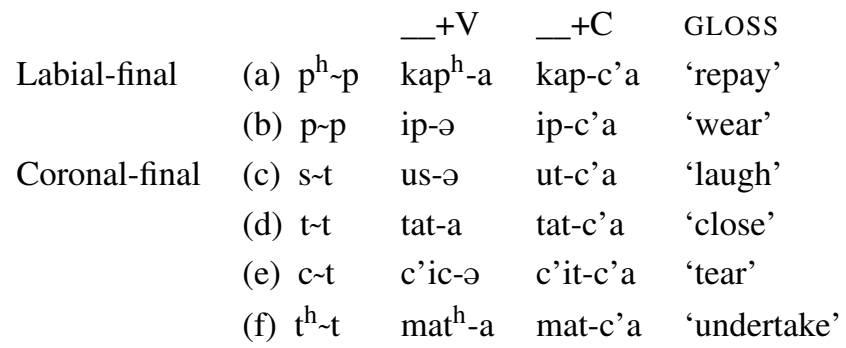

Coda neutralization is an exceptionless and fully productive process, and thus the pre- $\mathrm{C}$ form of a stem is fully predictable based on its corresponding pre- $\mathrm{V}$ form. In contrast, the stem-final segment of pre- $\mathrm{V}$ forms is unpredictable based on the pre- $\mathrm{C}$ form. Thus, even though the process of coda neutralization is exceptionless, the resulting allomorphy may involve unpredictability, depending on which form a speaker is presented with.

Coda neutralization is not the only source of alternations in Seoul Korean verbal paradigms. Additional cases in which pre- $\mathrm{V}$ forms are unpredictable based on their corresponding pre-C forms are shown in (3).

(3) Additional alternating classes with neutralized pre-C forms

$\begin{array}{lllll} & & \ldots+\mathrm{V} & \ldots+\mathrm{C} & \text { GLOSS } \\ \text { Labial-final } & \text { (a) } \mathrm{w} \sim \mathrm{p} & \text { tow-a } & \text { top-c'a } & \text { 'help' } \\ & \text { (a') } \mathrm{p} \sim \mathrm{p} & \text { ip-ə } & \text { ip-c'a } & \text { 'wear' } \\ \text { Coronal-final } & \text { (b) } \varnothing \sim \mathrm{t} & \text { ci-ə } & \text { cit-c'a } & \text { 'build' } \\ & \text { (b') } \mathrm{s} \sim \mathrm{t} & \text { us-ə } & \text { ut-c'a } & \text { 'laugh' } \\ & \text { (c) } 1 \sim \mathrm{t} & \text { tir-ə } & \text { tit-c'a } & \text { 'hear' } \\ & \text { (c') } \mathrm{t} \sim \mathrm{t} & \text { tat-a } & \text { tat-c'a } & \text { 'close' }\end{array}$

[3] Suffix-initial obstruents are always realized as tense in the presence of a preceding obstruent (post-obstruent tensing).

[4] Intervocalic stops become voiced due to inter-sonorant voicing. Thus, a more accurate phonetic transcription of [ipə] 'wear (IMP)' would be [ibə]. In addition, the liquid in Korean is realized as a lateral [1] except when it is a single onset, in which case it is realized as a flap [r]. These allophonic variations are not reflected in the transcription of this paper except where they are crucial to the discussion. 
In the traditional literature, the alternating classes $(3 a-c)$ are called ' $p, s, t-$ irregular'. The characterization as irregular reflects the fact that if these alternations are analyzed as intervocalic lenition (p-to-w spirantization, s-elision, and $\mathrm{t}$-flapping), they have numerous exceptions, exemplified in $\left(3 \mathrm{a}^{\prime}, \mathrm{b}^{\prime}, \mathrm{c}^{\prime}\right){ }^{5}{ }^{5}$ Stemfinally, each alternating class and its corresponding 'regular' class are distinct before V-initial suffixes whereas the two classes are neutralized before C-initial suffixes. Thus, as in the cases involving coda neutralization in (2) above, there is asymmetric (un)predictability: the pre- $\mathrm{V}$ forms here are unpredictable based on their corresponding pre- $\mathrm{C}$ forms.

Conversely, there are alternations in which the pre-C forms are unpredictable based on their corresponding pre- $\mathrm{V}$ forms, since neutralization occurs among pre$\mathrm{V}$ forms. Some examples are shown in (4).

(4) (Non-)alternating verb classes with neutralized pre-V forms

$\begin{array}{llllll} & & & -+\mathrm{V} & \ldots+\mathrm{C} & \text { GLOSS } \\ \text { Labial-final } & \text { (a) } w \sim \mathrm{u} & \text { sew-ə } & \text { seu-ca } & \text { 'erect' } \\ & \text { (a') } w \sim \mathrm{p} & \text { tow-a } & \text { top-c'a } & \text { 'help' } \\ \text { Coronal-final } & \text { (b) } 1 \sim 1 & \text { jər-ə } & \text { jəl-ca } & \text { 'open' } \\ & \text { (b') } 1 \sim \mathrm{t} & \text { tir-ə } & \text { tit-c'a } & \text { 'hear' }\end{array}$

Stem-final /u/ becomes [w] when a verb is conjugated with V-initial suffixes (glide formation), and thus the $u$-final stem class in (4a) would be indistinguishable prevocalically from the $\mathrm{w} \sim \mathrm{p}$ alternating class $\left(4 \mathrm{a}^{\prime}\right)$, which is traditionally called $\mathrm{p}$ irregular. Similarly, the 1-final stem class in (4b) is indistinguishable from the $1 \sim \mathrm{t}$ alternating class in $\left(4 \mathrm{~b}^{\prime}\right)$ (traditionally called $\mathrm{t}$-irregular) in the pre- $\mathrm{V}$ context, where both class stems end in a flap.

Thus far, we have presented cases in Seoul Korean verbal paradigms in which allomorphic alternations may be unpredictable, depending on which form of the verb is presented. In (2) and (3) above, pre-V forms are unpredictable based on their corresponding pre-C forms, whereas the opposite is true in (4). A consequence of this is that no single part of the paradigm suffices to tell a learner about whether and how all verb stems alternate. Nevertheless, many morphological and phonological analyses posit that a certain part of a paradigm is designated as the inflectional base for the entire paradigm, for all lexical items. The evidence for this hypothesis comes from acquisition errors (Do 2013), historical change (Kuryłowicz 1947, Mańczak 1958), and phonological paradigm uniformity effects (Kenstowicz 1996), all of which show that a single form in the paradigm may act

[5] For detailed descriptions and previous analyses of these irregular processes, see Chagyun Kim (1971), Chin-Wu Kim (1971), Lee (1976), Choi (1985), Han (1985), Kim-Renaud (1986), and $\operatorname{Kim}(1988)$.

[6] Stems with $\varnothing \sim \mathrm{t}$ alternations do not end in [s] in any part of their paradigms, despite the traditional class name of 's-irregular'. This name is based on the fact that these verbs contain $[\mathrm{s}]$ in standard Korean orthography (e.g. <cisko>) and in some non-standard dialectal pronunciations (e.g. [cit-c'a] [cis-ə]). 
as the 'pivot' or 'base' of reanalysis or paradigm uniformity. Albright (2002a) advances the 'single surface base' hypothesis, according to which learners choose a base form that maximizes predictability, by undergoing as few neutralizations as possible.

According to this hypothesis, the choice of the base form must be determined separately for each part of speech in each language. Kang (2006) provides empirical evidence from historical change and acquisition errors that pre- $\mathrm{V}$ forms act as the base of Korean verbal paradigms, and Albright \& Kang (2009) present learning simulation results showing that the pre- $\mathrm{V}$ form is indeed more informative than the pre- $\mathrm{C}$ form. If this is correct, then the grammar of Korean would consist of rules generating pre- $\mathrm{C}$ forms on the basis of the pre- $\mathrm{V}$ base, and not vice versa. Accordingly, we call the pre- $\mathrm{V} \rightarrow$ pre- $\mathrm{C}$ direction of inference 'forward formation', and pre-C $\rightarrow$ pre-V inference 'backward formation'. We should emphasize that the distinction between forward and backward formation follows from asymmetrical grammatical models with a designated base. The goal of this study is to test the hypothesis that grammar is asymmetrical, and consists only of knowledge of 'forward' mappings. In the wug tests described in Section 2 below, participants were presented with forms of nonce verbs showing neutralizations in pre- $\mathrm{V}$ and pre-C contexts, and asked to generate unpredictable forms. If the single base hypothesis is correct, speakers would learn the statistical trends governing pre- $\mathrm{V} \rightarrow$ pre-C projection, but not the reverse. The wug test results in Section 3 will provide evidence in favor of this hypothesis.

\subsection{Morphological correspondence rules in Seoul Korean verbal paradigms}

In this section, we first describe the statistical trends governing (non-)alternation in Seoul Korean verbal paradigms, in both the forward and backward formation directions. We then compare several models of how speakers may select allomorphs based on these trends, and their predictions for the wug tests that we carried out on Seoul Korean verbal paradigms.

\subsubsection{The minimal generalization learner}

For the purpose of obtaining probabilistic rules relating surface allomorphs in Seoul Korean verbal paradigms, we employed the minimal generalization learner proposed by Albright \& Hayes (2002, 2003) and Albright (2005). To illustrate, consider the following pairs of Seoul Korean verb forms (designated here with numerals to relate them to the rules in (6) below). 
(5) Example pairs of inflected verb forms in Seoul Korean

$\begin{array}{lllll} & \text { PRE-V } & & \text { PRE-C } & \text { GLOSS } \\ \text { i. } & \text { ipə } & \sim & \text { ipc'a } & \text { 'wear' } \\ \text { ii. } & \text { s'ipə } & \sim & \text { s'ipc'a } & \text { 'chew' } \\ \text { iii. } & \text { әрә } & \sim & \text { әрc'a } & \text { 'carry someone on one's back' } \\ \text { iv. } & \text { nuwə } & \sim & \text { nupc'a } & \text { 'lie' } \\ \text { v. } & \text { cuwə } & \sim & \text { cupc'a } & \text { 'pick up' } \\ \text { vi. } & \text { kiwə } & \sim & \text { kipc'a } & \text { 'sew' }\end{array}$

The goal of the model is to learn a set of rules mapping one form (such as the pre$\mathrm{V}$ form) to another (such as the pre- $\mathrm{C}$ form). Rules have the form $\mathrm{A} \rightarrow \mathrm{B} / \mathrm{C} \_\mathrm{D}$, consisting of a structural change $(\mathrm{A} \rightarrow \mathrm{B})$ and context, or structural description (C_D $)$. In order to identify the structural change and context, morphologically related pairs of forms are compared, e.g. [ipə] and [ipc'a]. The substring that the two forms have in common is taken as the context, and the part that differs as the change. This initial comparison for the paradigms in (5), in both the pre- $\mathrm{V} \rightarrow$ pre- $\mathrm{C}$ and pre- $\mathrm{C} \rightarrow$ pre- $\mathrm{V}$ directions, yields the set of word-specific rules in (6).

(6) Word-specific rules

(a) Forward formation

i. $\left[\right.$ [ə] $\rightarrow\left[c^{\prime}\right.$ a $] /$ ip _ \#

ii. [ə] $\rightarrow$ [c'a] / s'ip _\#

iii. [ə] $\rightarrow$ [c'a] / əp _\# \#

iv. $[\mathrm{w} \partial] \rightarrow[\mathrm{pc}$ 'a] $/ \mathrm{nu} \ldots$

v. $[$ wə] $\rightarrow$ [pc'a] / cu _\#

vi. [wə] $\rightarrow$ [pc'a] / ki _ \#

(b) Backward formation

i. $\quad\left[c^{\prime} a\right] \rightarrow[ə] /$ ip _ \#

ii. $\left[c^{\prime} a\right] \rightarrow[ə] / s^{\prime}$ ip _ \#

iii. [c'a] $\rightarrow$ [ə] / əp __\#

iv. [pc'a] $\rightarrow$ [wə] / nu _\#

v. [pc'a] $\rightarrow$ [wə] / cu _\#

vi. [pc'a] $\rightarrow$ [wə] / ki _\#

These word-specific rules are in turn compared, and if a pair of rules share the structural change, their contexts are compared in order to create a more general rule. For instance, the rules in (6a.ii, iii) share the change [ə] $\rightarrow$ [c'a], so they are compared to determine more general ways to characterize the environments in which the change occurs, as illustrated below: 
(7) Generalization over pairs of related rules

\begin{tabular}{|c|c|c|c|c|c|}
\hline Change & Residue & $\begin{array}{l}\text { Shared } \\
\text { features }\end{array}$ & $\begin{array}{c}\text { Shared } \\
\text { segments }\end{array}$ & $\begin{array}{l}\text { Change } \\
\text { location }\end{array}$ & $\begin{array}{c}\text { Shared } \\
\text { segments }\end{array}$ \\
\hline$\partial \rightarrow c^{\prime} a$ & s' & $\mathrm{i}$ & $\mathrm{p}$ & - & \# \\
\hline$\partial \rightarrow c^{\prime} a$ & $\varnothing$ & Ә & $\mathrm{p}$ & - & \# \\
\hline$\partial \rightarrow c^{\prime} a$ & $X$ & $\begin{array}{l}\text { +syl } \\
- \text { cons } \\
\text {-low } \\
\text { - round } \\
\text { etc. }\end{array}$ & $\mathrm{p}$ & - & \# \\
\hline
\end{tabular}

Note: $\varnothing$ stands for the null string, and $\mathrm{X}$ is a free variable.

Common properties on the left and right sides of the 'change location', shown under 'shared segments/features' above, form the context of a new generalized rule. The remaining material with no common properties, shown under 'residue' above, is represented as a free variable $(\mathrm{X})$. Some resulting generalized rules for the paradigms in (5) would be the following:

(8) Generalized rules

(a) Forward formation
i. $\quad[ə] \rightarrow\left[c^{\prime} a\right] / X i p$
(from 6a.i-ii)
ii. $[ə] \rightarrow\left[c^{\prime} a\right] / X\left[\begin{array}{c}+ \text { syl } \\ - \text { low } \\ \text { etc. }\end{array}\right] p_{\ldots} \# \quad$ (from 6a.i-iii)
iii. $\quad[\mathrm{w} \partial] \rightarrow\left[\mathrm{pc}^{\prime} \mathrm{a}\right] / \mathrm{Xu}$
(from 6a.iv-v)

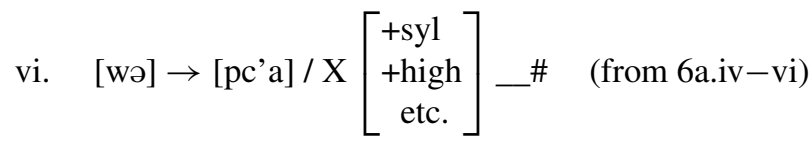


(b) Backward formation

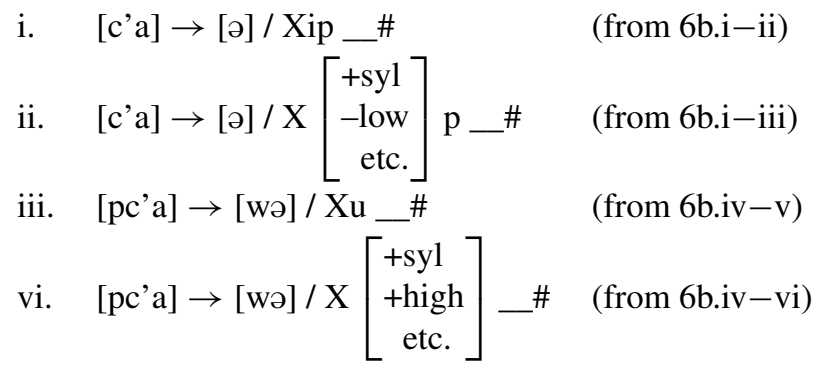

Comparisons of this type are iterated, yielding multiple rules for the same change. The resulting contexts can be very general, if the pairs of rules being compared do not share many segments or features in the context.

This comparison procedure yields many rules for the same change, and frequently a given word will be covered by multiple rules. For example, (5i) [ipə] is covered in the backward formation direction by rules (6b.i), (8b.i), and (8b.ii). However, these rules differ in their statistical validity: the rule in (6b.i) narrowly and accurately characterizes (5i) 'wear', but it does not generalize to any other lexical items. Rules (8b.i) and (8b.ii), on the other hand, are more broadly applicable, but at the cost of including some exceptions, such as (5vi) [kipc'a], which is [kiwə], not *[kipə] in the pre-V form. It is hypothesized that learners seek rules that cover as many items and include as few exceptions as possible. In order to determine this, the model calculates the reliability of each rule, as defined in (9).

(9) Definition of a rule's reliability (Albright 2005: ex. (10))

$$
\text { Reliability }=\frac{\# \text { of forms included in the rule's structural change }(=\text { hits })}{\# \text { of forms included in the rule's structural description }(=\text { scope })}
$$

For instance, as shown below, the structural description of the generalized rule in (8b.i) is met in eight forms in the Seoul Korean verb lexicon employed in the present study, but only six of them, shown in (10a), take the structural change of the rule. (We explain how the verb lexicon was constructed later in this section, before example (11).) Two verbs, presented in (10b, c), show different changes involving $\mathrm{p} \rightarrow \mathrm{w}$ and $\mathrm{p} \rightarrow \mathrm{p}^{\mathrm{h}}$, respectively, and thus count as exceptions, rather than as hits, for rule (8b.i). 
(10)

Words meeting the structural description of the rule in (8b.i)

(a)

${ }_{\mathrm{p} \sim \mathrm{p}}^{(\mathrm{NON}-) \text { ALTERNATION }}$

(b) $\quad w \sim p$

(c) $\mathrm{p}^{\mathrm{h}} \sim \mathrm{p}$

\begin{tabular}{|c|c|c|}
\hline$+\mathrm{V}$ & $-+\mathrm{C}$ & GLOSS \\
\hline k'ocip-ə & k'ocip-c'a & 'pinch' \\
\hline picip-ə & picip -c'a & 'squeeze in' \\
\hline s’ip-ə & s'ip-c'a & 'chew' \\
\hline ip-ə & ip-c'a & 'put on' \\
\hline cip-ə & cip-c'a & 'pick up' \\
\hline hесір-ә & hecip-c'a & 'dig up' \\
\hline kiw-ə & kip-c'a & ‘sew’ \\
\hline $\operatorname{cip}^{h}-\partial$ & cip-c'a & 'place one's hand on' \\
\hline
\end{tabular}

As a result, rule (8b.i) has a reliability of $6 / 8=0.75$.

The reliability of a rule indicates the probability of the rule's application in the lexicon. Recall that the objective of the model is to find those rules that cover as many forms as possible; however, rules that cover just a single word, such as the rules in (6) above, have very high reliability (typically, $1 / 1=1$ ). Therefore, the raw reliability values are adjusted using lower confidence limit statistics (Mikheev 1997) to yield confidence values. In the calculation of confidence, ratios that are based on smaller amounts of data (i.e. reliabilities with smaller scope) are penalized more than rules based on larger amounts of data (higher scope). For instance, a rule with $5 / 5$ reliability is assigned a lower confidence value than the one with 1000/1000 reliability. When a confidence level of $\alpha=0.95$ is adopted, the former has a confidence of 0.825 and the latter has a confidence of 0.999 . The confidence of the rule in (8bi), which has a reliability of 0.75 , is 0.609 .

We assume that speakers select the best rule for each change, i.e. the one with highest confidence among those that can apply, when they produce output forms of an unknown stem and rate its well-formedness. Accordingly, speakers' wellformedness ratings on the output forms are determined by the confidence value of the best rule. When a nonce form is covered by a rule that has high scope and few exceptions, the relevant change will apply with high confidence; thus, high lexical frequency supports confident generalization, or high productivity, of a pattern of allomorphy.

In order to construct a full set of rules for deriving pre- $\mathrm{V}$ and pre-C allomorphs in Seoul Korean verbal paradigms and calculate their reliability/confidence values, we need a lexicon of Seoul Korean verbs. To construct this, we started with a list of Korean verbs provided by Kang \& Kim (2004), which is based on a 5.5 million word text corpus of Sejong Project (http://www.sejong.or.kr/). Since the Seoul dialect may roughly be considered the standard dialect of Korean, we used the Standard Korean Dictionary (Kwuklip kwuke yenkwuwen 1999) to exclude typographical and classification errors, non-standard dialectal and polymorphemic verbs. We also excluded those whose token frequencies are below 10 in the Sejong Corpus, since the first author, who is a native speaker of Seoul Korean, mostly did not recognize these low-frequency verbs, which we take to 
suggest that these are sufficiently rare and should therefore be excluded from the construction of a lexicon of Seoul Korean verbs. The resulting database included inflected pre-C and pre-V forms of 722 verbs. This set of verbs was then submitted to the minimal generalization learner, in order to obtain lexical frequencies of each (non-)alternation class and a full set of forward and backward formation rules. Some of the resulting rules are shown in (11).

\section{(11) Example rules for Seoul Korean verbal paradigms}

(a) Forward formation

\begin{tabular}{|c|c|c|c|c|}
\hline Rule & Hit/scope & Reliability & Confidence & Hits/exceptions $^{7}$ \\
\hline i. $\quad[w ə] \rightarrow[p c ' a] /\left[\begin{array}{l}+ \text { syl } \\
+ \text { high }\end{array}\right]$ \# $^{\prime}$ & $5 / 10$ & 0.5 & 0.389 & 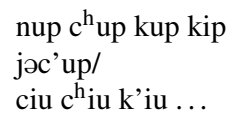 \\
\hline ii. $[\mathrm{l} ə] \rightarrow\left[\mathrm{tc}^{\prime} \mathrm{a}\right] / \mathrm{V}_{\text {— }} \#$ & $8 / 89$ & 0.089 & 0.073 & $\begin{array}{l}\text { tit mut kət k'etat sit } \\
\ldots . / \\
\text { al sal mantil til ... }\end{array}$ \\
\hline iii. $[ə] \rightarrow\left[c^{\prime} a\right] / V p_{-} \#$ & $11 / 11$ & 1 & 0.916 & $\begin{array}{l}\text { cap ip cip s'ip } \\
\text { cəp } \ldots / \\
\text { (no exceptions) }\end{array}$ \\
\hline iv. [ə] $\rightarrow\left[\mathrm{c}^{\prime} \mathrm{a}\right] / \mathrm{Vt} \ldots$ & $11 / 11$ & 1 & 0.916 & $\begin{array}{l}\text { pat ət mit p'ət } \\
\text { tat t'it .../ } \\
\text { (no exceptions) }\end{array}$ \\
\hline v. $\quad[\mathrm{s} \partial] \rightarrow\left[\mathrm{tc}^{\prime} \mathrm{a}\right] / \mathrm{V}_{-} \#$ & $7 / 7$ & 1 & 0.872 & $\begin{array}{l}\text { us pəs s'is p'eas } \\
\text { pius .../ } \\
\text { (no exceptions) }\end{array}$ \\
\hline vi. $[\mathrm{c} \partial] \rightarrow\left[\mathrm{tc}^{\prime} \mathrm{a}\right] / \mathrm{V}_{\ldots} \#$ & $15 / 31$ & 0.483 & 0.423 & $\begin{array}{l}\mathrm{c}^{\mathrm{h}} \text { ac mac ic mec } \\
\text { cəc .../ } \\
\text { kaci p'aci salaci } \\
\mathrm{t}^{\mathrm{h}} \text { əci t'aci ... }\end{array}$ \\
\hline vii. $[\mathrm{c} \partial] \rightarrow\left[\mathrm{tc}^{\prime} \mathrm{a}\right] / \mathrm{i} \_\#$ & $7 / 8$ & 0.875 & 0.740 & $\begin{array}{l}\text { ic pic c'ic cic } \\
\text { k'ucic .../ } \\
\text { cici }\end{array}$ \\
\hline
\end{tabular}

[7] For ease of interpretation, the relevant verb stems are shown in their conventional citation forms, rather than the pre-V (forward) or pre-C (backward) forms. 
(b) Backward formation

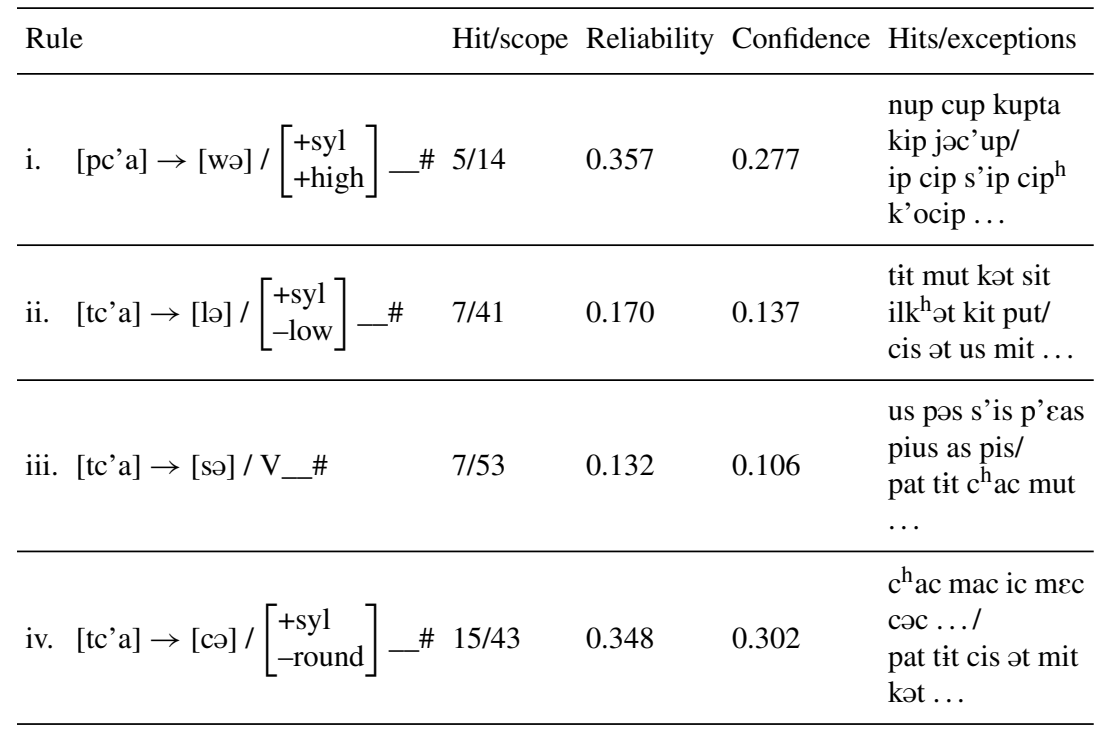

Recall from Section 1.1 that the pre- $\mathrm{V}$ forms of the $\mathrm{w} \sim \mathrm{p}$ and $1 \sim \mathrm{t}$ alternating classes are not distinguishable with respect to stem-final segments from those of the regular $\mathrm{u}$-final stems $(\mathrm{w} \sim \mathrm{u})$ and l-final stems $(1 \sim 1)$, respectively. Thus, as can be seen in the last column of (11a.i, ii), the u- and l-final stems are exceptions to the forward formation rules for the $\mathrm{w} \sim \mathrm{p}$ and $1 \sim \mathrm{t}$ alternating classes, which accounts for their relatively low confidence values $(0.389$ and 0.073$)$. In contrast, the forward formation rules for non-alternation, i.e. (11a.iii) $\mathrm{p} \sim \mathrm{p}$ and (11a.iv) $\mathrm{t} \sim \mathrm{t}$, and that for the $s \sim t$ alternation (11a.v) resulting from coda neutralization all have high confidence values, since none of these classes involve neutralization in the base (pre-V) form. Therefore, all stems ending with [p], [t], or [s] in pre-V position have $[\mathrm{p}],[\mathrm{t}]$ and $[\mathrm{t}]$ in pre-C position, and there are no exceptions to the rules in (11a.iii-v). (The alternations involved in /c/- and /ci/-final verbs in (11a.vi, vii) will be discussed later in this section.)

It was also noted in Section 1.1 that in pre-C position, the $w \sim p$ alternating class is neutralized with the $\mathrm{p} \sim \mathrm{p}$ and $\mathrm{p}^{\mathrm{h}} \sim \mathrm{p}$ (non-)alternating classes, and similarly, the $1 \sim t$ alternating class is neutralized with (non-)alternations like $s \sim t, c \sim t, t \sim t$, etc. Thus, in the backward formation direction, there is stiff competition between several different patterns for each place of articulation, which leads to exceptions. Thus, backward formation rules, some of which are shown in (11b) above, tend to have relatively low confidence values; the values $0.106-0.302$ in (11b) are typical.

There are two points that merit comment. First, the rules for an alternation class may have drastically different confidence values depending on the direction of the derivation. For instance, the forward formation rule for the $s \sim t$ alternation (11a.v) has a high confidence of 0.872 , whereas its backward formation counterpart 
(11b.iii) has a low confidence of 0.106 . This is because different parts of the paradigm are affected by different neutralizations, so a given alternation class may compete with different sets of alternation classes in forward and backward formations. In the forward formation, as mentioned above, the $s \sim t$ alternation class has no competition, since all stems, ending with [s] before V-initial suffixes, must end with [t] before C-initial suffixes. Thus, the forward formation rule for the $s \sim \mathrm{t}$ alternation has no exceptions, resulting in high confidence. In contrast, in the backward formation direction, the $s \sim t$ alternation class competes with many other classes, including $\mathrm{t} \sim \mathrm{t}, \mathrm{c} \sim \mathrm{t}$, and $\mathrm{l} \sim \mathrm{t}$, which end with coronal consonants other than [s] before V-initial suffixes. Thus, the backward formation rules for coronal-final classes usually have many exceptions, obtaining low confidence values. Cases like this, where forward and backward formation rules have distinct reliability/confidence values, will be crucial in the testing of possible models of allomorph selection.

In addition, it can happen that an alternation is relatively unreliable in general, but highly reliable in a specific environment. In the above, the forward formation rule for the $\mathrm{c} \sim \mathrm{t}$ alternation, shown in (11a.vi), with a relatively broad rule context, has a medium confidence value of 0.423 , because almost as many verb stems show the c ci alternation where stem-final /i/ before a suffix-initial vowel undergoes glide formation nearly obligatorily, and the resulting [j] deletes after an affricate (post-affricate /i/-deletion). But, if we limit ourselves to pre-V forms where final /c/ follows /i/, the relevant rule for the $\mathrm{c}$ t alternation, shown in (11a.vii), has a relatively high confidence value of 0.740 since seven out of eight stems that end with [it] in their pre-C forms are /c/-final, not /ci/-final. This context-specific rule predicts that Seoul Korean speakers will choose [t]-final forms for wug verb stimuli with final [ic] before V-initial suffixes to an above-average extent. This is what Albright (2002b) calls an 'island of reliability'. The prediction is that an alternation pattern may be more productive in those specific contexts, where the proportion of items undergoing the rule is especially high in the lexicon. Thus, it is possible that the speakers' responses for wug stems with identical final segments will differ depending on the specific quality of non-final segments.

\subsubsection{Single base hypothesis and backward formation}

The single base hypothesis states that one form, i.e. the privileged base form, is memorized and the rest of the paradigm is derived from it. (See Albright 2002a, 2005 for details of the single base hypothesis.) Under the strictest version of this hypothesis, speakers have only forward formation rules deriving non-base forms from the base, and no backward formation rules deriving the base form from a non-base form are available to them. (Under a more relaxed version of a single base hypothesis, backward formation rules exist, but are limited in their application in some way.)

To illustrate the consequences of this hypothesis, consider a case in which the confidence values of the rules deriving a particular alternation are very different in the forward and backward formation directions. Recall that the forward formation 
rule for the $s \sim t$ alternation has a relatively high confidence of 0.872 whereas its corresponding backward formation counterpart has a low confidence of 0.106 . In a fully symmetrical model, in which all forms can be derived directly from each other, both sets of forward and backward formation rules accompanied with their probability of application, i.e. reliability/confidence, are available. The expected productivities of the $s \sim t$ alternation are then different depending on the direction of the wug test. Participants in the forward formation test, given a stimulus ending with [s] should be relatively likely to produce responses ending with [t], while participants in a backward formation test, given a stimulus ending with [t], should be relatively unlikely to produce [s]. We will call this model a 'bi-directional' model. We also note in passing that a number of theoretical approaches to encoding alternations with underlying forms (rather than rules encoding surface mappings) are also 'bi-directional', in that they allow speakers to consider information from any part of the paradigm when projecting other forms. ${ }^{8}$ If the distribution of responses in the backward formation test matches well the confidence of backward formation rules, it would lead us to reject the single base hypothesis, in favor of a bi-directional model.

In contrast, under the single base hypothesis, the grammar contains no backward formation rules. Thus, we must ask what speakers do in a situation where they must provide a base form for the given non-base form of an unknown stem, such as in a backward formation wug test. Lacking rules to derive base forms directly, there are several mechanisms that speakers might employ to infer base forms, when given a non-base stimulus. Some possibilities are listed in (12).

\section{(12) Possible mechanisms for backward formation}

(a) Using forward formation rules in reverse

(b) Random guessing

(c) Paradigm uniformity

[8] In many 'traditional' approaches to phonological analysis, speakers infer underlying forms by considering all available surface allomorphs together. For example, many Seoul Korean verb stems end with coronal obstruents such as $/ \mathrm{s}, \mathrm{t}, \mathrm{c}, \mathrm{c}^{\mathrm{h}}, \mathrm{t}^{\mathrm{h}}$, etc./ in pre-V forms, but surface with [t] in pre-C forms due to coda neutralization. If speakers are given only a pre-C form of a novel verb, they must guess which underlying value to posit for the stem-final segment. If they make this guess on the basis of lexical statistics, the probability of choosing /s/ would be very low, just like the rule mapping surface $t \rightarrow s$ in the bi-directional model. Thus, the frequency-based inference mechanism of the bi-directional model that we describe here is widely assumed, at least implicitly, in phonological analyses. See Pater et al. (2012) for an alternative employing multiple underlying representations in explaining intraparadigmatic alternations. 
The first possibility is that speakers employ forward, not backward, formation rules, even when doing a 'backward formation' task. If, as suggested by the single base hypothesis, no other rules than forward formation rules are available, speakers might rely on them even in a backward formation test by undoing them. In forward application, speakers take a given stimulus as input, and check which rules it could undergo (i.e. meets the structural description). In order to apply forward rules to a backward formation, speakers would need to determine which rules a given stimulus could have been produced by, as the output for the rule. Thus, inference in both directions employs the same set of rules, but sometimes through regular application (forward formation) and sometimes by inferring possible outputs (backward formation). We will call this a 'uni-directional model'. For example, given a Seoul Korean verb stem ending with [t] before a consonant (a non-base form), speakers would need to identify rules that have [t] as their output, such as the $\mathrm{t} \rightarrow \mathrm{t}$ rule in (11a.iv) (confidence $=0.916$ ), the $\mathrm{s} \rightarrow \mathrm{t}$ rule in (11a.v) (confidence $=0.872$ ) and many others. If speakers' task in the wug test is to rate the well-formedness of possible inflected forms, they would assign high scores, close to 0.872 (out of 1.0), to the forms ending with [s]. Note that this wellformedness rating is very different from the corresponding backward formation rule's prediction, 0.106 . This kind of result would strongly support the single base hypothesis over the bi-directional model. If speakers have both forward and backward formation rules, there would be no plausible reason for using FORWARD formation rules in the BACKWARD formation test. It will be shown that the uni-directional model makes better predictions about the distribution of the participants' response patterns of the present experiment than the bi-directional model and other alternatives, supporting the single base hypothesis.

There are other conceivable approaches to projecting base forms in the backward direction, even if backward formation rules are not available. One straightforward and uninteresting possibility is random guessing; this predicts that speakers should simply assign equal probability to all possible patterns. Alternatively, speakers might choose the response that best satisfies paradigm uniformity constraints (Kenstowicz 1995, 1996; Benua 1997; Steriade 2000; Coetzee 2009). If speakers were found to mirror lexical statistics in the forward direction, while employing random guessing or favoring uniformity only in the backward formation direction, this would also support an asymmetrical model such as the single base hypothesis. However, if speakers behave randomly or based on Paradigm Uniformity in ВОтн forward and backward formation tests, it would simply mean that speakers do not know any statistical patterns in the lexicon, providing counter-evidence to all stochastic approaches relying on lexical patterns. (See Coetzee 2009 for the claim that Paradigm Uniformity is the default option in learning the relation between surface forms in a paradigm.)

In order to collect data to test the alternative models just discussed, we performed wug tests on Seoul Korean verbal paradigms. 


\section{EXPERIMENT: WUG TEST}

\subsection{Participants}

Forty-two paid native speakers of Seoul-Gyeonggi dialects were recruited from the community at Seoul National University. Twenty-two and twenty participated in forward and backward formation tests, respectively. No one participated in both tests. See Appendix A for details of the experiment.

\subsection{Materials}

Korean wug verbs were created through minor modification of Middle Korean verbs and adjectives listed in Lee (2008). ${ }^{9}$ The same set of wug stems was employed in both forward and backward formation tests. In order to test the productivity of alternations, the stem-final segments were varied in the pre-V (base) and pre-C (derived) forms in order to create novel members of each target alternation class. All of the wug verbs were inflected with verbal endings such as imperative and hortative markers, which can only attach to verbs and not to other categories such as nouns and adjectives. All the inflected forms employed in the experiment can be seen in Appendix B.

In both the forward and backward formation tests, 20 test stems and 20 fillers (10 k-final and $10 \mathrm{~m}$-final) were employed. The test stems were designed to test the productivity of alternations such as $w \sim p, 1 \sim t, \varnothing \sim t, s \sim t$, and $c \sim t$. In the forward formation test, half of the test stems ended in [w] and the rest ended in [1], allowing us to test the productivity of the alternations $w \sim p$ and $1 \sim \mathrm{t}$. In the backward formation test, half of the test stems ended in [p] and the rest ended in [t], allowing us to test the productivity of not only the alternations $\mathrm{w} \sim \mathrm{p}$ and $1 \sim \mathrm{t}$ but also those involving coronal neutralizations such as $\varnothing \sim \mathrm{t}, \mathrm{s} \sim \mathrm{t}$, and $\mathrm{c} \sim \mathrm{t}$.

\subsection{Method}

In the present experiment, modeled on Albright \& Hayes (2003), participants were required to perform the following three tasks:

[9] After the experiment was completed, it was found that among these words, three are listed as real Korean verbs or adjectives in the Standard Korean Dictionary (Kwuklip kwuke yenkwuwen 1999): /kjət/ 'become greasy' is a verb with $\varnothing \sim \mathrm{t}$ alternation (t-irregular), /nep/ 'smoky' is an adjective with $\mathrm{w} \sim \mathrm{p}$ alternation (p-irregular) and /kamjəl/ 'rich' is an 1-final adjective. They are not known to the first author, a native speaker of Seoul Korean, and their token frequency is quite low, below 10 in Sejong Corpus (Kang \& Kim 2004). Furthermore, it turned out from the results of the current wug test that no participants produced a t-irregular form for $/ \mathrm{kj}$ t/, and only one participant produced a p-irregular form for $/ \mathrm{n} \varepsilon \mathrm{p} /$, strongly suggesting that they are novel words for the participants as well. None of the three words showed different response patterns from the rest of stimuli in the same group. Thus, all the stems employed in this experiment can be considered wug verbs in contemporary Korean. 
(13) Tasks

(i) Phonological well-formedness judgment of the wug verb stimuli

(ii) Production of inflected forms of wug verbs

(iii) Goodness judgment of possible inflected forms of wug verbs

Task (i) was adopted for two purposes: to hide the intention of the experiment from the participants and to confirm that the stimuli sounded phonologically natural to them.

For task (ii), participants produced inflected forms of the given wug verbs. In forward formation test, the wug verb stimuli were presented in their pre- $\mathrm{V}$ forms, and the participants produced pre- $\mathrm{C}$ forms as responses. Both pre- $\mathrm{V}$ and pre- $\mathrm{C}$ forms were placed in a frame consisting of four sentences as shown below:

Frame sentences in the forward formation test

\section{SENTENCES}

(a) nuka [wug verb]?

'who'

(b) Ch $\mathrm{C}^{\mathrm{h}}$ lsu-ka [wug verb]. 'proper name-NOM'

(c) Ch $\mathrm{C}^{\mathrm{h}}$ əlsu-ja [wug verb]! 'proper name-VOC'

(d) uli-to [wug verb]! 'we-too'
INFLECTION TYPE

Interrogative (pre-V)

Declarative (pre-V)

Imperative (pre-V)

Hortative (pre-C)
PRODUCED BY...

Experimenter

Experimenter

Participant

Participant

In backward formation test, the opposite applied: stimuli were presented in their pre- $\mathrm{C}$ forms, and participants produced the corresponding pre- $\mathrm{V}$ forms.

For task (iii), the participants rated various possible inflected forms of the given wug verbs according to how acceptable they sounded as inflected forms of the given stimuli. In forward formation test, participants were given wug verbs in pre$\mathrm{V}$ forms, and provided acceptability ratings of possible pre-C forms. Conversely, in the backward formation test, participants were given wug verbs in their pre-C form, and provided acceptability ratings of possible pre- $V$ forms. In this part of the experiment, each wug verb was embedded in a frame consisting of two sentences, as can be seen in (15)-(16) below. The inflected form of a wug verb in the first sentence can be considered as a stimulus, and the one in the second sentence, a 'response', conditioned on the first form that was presented. In forward formation test, test stems ending in [w] in the base form were presented with [p] and [u] for rating, while stems ending in [1] were presented with [t] and [1] for rating, as in (15). 
(15) Example experimental sentences of the goodness judgment portion: Forward formation

(C $\mathrm{C}^{\mathrm{h}}$ əlsu-ja 'proper name-VoC'; uli-to 'we-too')

(a) w-final

TESTING CLASS EXPERIMENTAL SENTENCES
i. $\mathrm{W} \sim \mathrm{p}$
Ch əlsu-ja nasuw-ə!
(imperative)
uli-to nasup-ca!
(hortative)
ii. $\mathrm{W} \sim \mathrm{U}$
$\mathrm{C}^{\mathrm{h}}$ əlsu-ja nasuw-ə!
(imperative)
uli-to nasuu-ca!
(hortative)

(b) 1-final

TESTING CLASS EXPERIMENTAL SENTENCES

$\begin{array}{lll}\text { i. 1 t } & \mathrm{C}^{\mathrm{h}} \text { əlsu-ja kamjəl-ə! } & \text { (imperative) } \\ \text { ii. } 1 \sim 1 & \text { uli-to kamjət-ca! } & \text { (hortative) } \\ & \mathrm{C}^{\mathrm{h}} \text { əlsu-ja kamjəl-ə! } & \text { (imperative) } \\ & \text { uli-to kamjəl-ca! } & \text { (hortative) }\end{array}$

In backward formation test, test stems ending in [p] in the non-base (pre-C) form were presented with [p] and [w] for rating, while test stems ending in [t] were presented with the five possible segments $[1, \mathrm{t}, \varnothing, \mathrm{s}, \mathrm{c}]$ for rating.

(16) Example experimental sentences of the goodness judgment portion: Backward formation

(a) p-final

TESTING CLASS EXPERIMENTAL SENTENCES

$\begin{array}{lll}\text { i. } w \sim \mathrm{p} & \text { uli-to nasup-ca! } & \text { (hortative) } \\ & \mathrm{C}^{\mathrm{h}} \text { əlsu-ja nasuw-ə! } & \text { (imperative) } \\ \text { ii. } \mathrm{p} \sim \mathrm{p} & \text { uli-to nasup-ca! } & \text { (hortative) } \\ & \mathrm{C}^{\mathrm{h}} \text { əlsu-ja nasup-ə! } & \text { (imperative) }\end{array}$

(b) t-final

\begin{tabular}{|c|c|c|}
\hline TESTING CLASS & EXPERIMENTAL SENTENCES & \\
\hline \multirow[t]{2}{*}{ i. $1 \sim \mathrm{t}$} & uli-to kamjət-ca! & (hortative) \\
\hline & $\mathrm{C}^{\mathrm{h}}$ əlsu-ja kamjəl-ə! & (imperative) \\
\hline \multirow[t]{2}{*}{ ii. $\mathrm{t} \sim \mathrm{t}$} & uli-to kamjət-ca! & (hortative) \\
\hline & $\mathrm{C}^{\mathrm{h}}$ əlsu-ja kamjət-ə! & (imperative) \\
\hline \multirow[t]{2}{*}{ iii. $\varnothing \sim \mathrm{t}$} & uli-to kamjət-ca! & (hortative) \\
\hline & $\mathrm{C}^{\mathrm{h}}$ əlsu-ja kamjə-ə! & (imperative) \\
\hline \multirow[t]{2}{*}{ iv. $s \sim t$} & uli-to kamjət-ca! & (hortative) \\
\hline & $\mathrm{C}^{\mathrm{h}}$ əlsu-ja kamjəs-ə! & (imperative) \\
\hline \multirow[t]{2}{*}{ v. $c \sim t$} & uli-to kamjət-ca! & (hortative) \\
\hline & $\mathrm{C}^{\mathrm{h}}$ əlsu-ja kamjəc-ə! & (imperative) \\
\hline
\end{tabular}


In the experiment, items were ordered such that pairs of sentences for competing (non-)alternation classes were never adjacent to each other. For instance, the pairs in (16a.i) and (16a.ii) were presented as far from each other as possible. The experimenter also emphasized that the participants must rate the goodness of the second occurrence of the wug verb, considering how good it was as a hortative form (or imperative form in backward formation test) of the novel verb presented in the first sentence. For each wug verb, the experimenter produced the two frame sentences, using an appropriate intonation. Throughout the experiment, only spoken forms of wug verbs were used by both the experimenter (the first author or his assistant) and participants. The remaining details of the experimental procedure are given in Appendix A.

\subsection{Results}

In this section, we first report participants' phonological well-formedness judgments for the experimental stimuli, and then their productions and acceptability judgments for possible inflected forms of the wug verbs.

\subsubsection{Phonological well-formedness}

In order to minimize the possibility that the experimental stimuli contain phonologically unnatural sequences, most stimuli were created through minor modification of real but obsolete Middle Korean verbs or adjectives, which are phonotactically similar to words that survived into Modern Korean. This helped to ensure that the items would be legal Korean words, but it is still important to confirm that the invented Korean wug verbs were considered phonologically natural by speakers of Modern Korean. Furthermore, by collecting phonological well-formedness ratings of each verb, we were able to control statistically for any effect that small differences in phonotactic wellformedness between the verbs may have had on participants' ratings on the goodness of the inflected forms of the verbs.

The average of participants' phonological ratings for our wug verbs is 4.09 (mean rating of pre-C forms $=4.21, \mathrm{SD}=0.90, \mathrm{n}=20$; mean rating of pre- $\mathrm{V}$ forms $=3.98, \mathrm{SD}=0.57, \mathrm{n}=20$ ). These phonological ratings can be compared to those of Albright \& Hayes's (2003) wug verbs, which were designed to be well-formed English words. On the same 1-7 scale $(1=$ completely bizarre; $7=$ completely normal), their English wug verbs received $4.68(\mathrm{SD}=1.62, \mathrm{n}=58)$ and ill-formed foils, 2.97 ( $\mathrm{SD}=1.46, \mathrm{n}=29$ ). Thus, although Korean wug verbs in general received lower phonological ratings than English wug verbs, their ratings are closer to those of English wug verbs and clearly higher than those of English ill-formed foils.

In addition, three low-frequency real words were mistakenly employed as wug verb stimuli in the present experiment (see footnote 9), allowing us to compare phonological ratings for 'truly' nonce verbs against a few actual Korean verbs. 
The mean phonological rating for one of the real verbs [kamjəl-ə] is 3.36, which is lower than the ratings of most of the wug verbs (16 out of 20 pre-V forms). In other words, most of the wug verbs received higher phonological ratings than at least one real word. This suggests that participants in general found the wug verb stimuli to be relatively acceptable, on par with actual (but obsolete) Korean verbs.

Recall that our primary reason for wanting wug stimuli to sound like ORDINARY Korean verbs is that we do not want speakers to reject inflected forms because they contain phonotactically improbable sequences (rather than improbable alternations). Thus, it is relevant to observe that participants' phonological ratings of the wug verbs are not strongly correlated with their ratings of the inflected forms. The correlation values, which are not statistically significant, are quite low, as shown in (17).

(17) Correlations between phonological ratings and goodness ratings of the inflected forms

(a) Forward formation test: $r(40)=0.09$

(b) Backward formation test: $r(70)=0.15$

Consequently, we can be sure that participants did not rate the goodness of the inflected forms according to their phonological well-formedness. In Section 3 below, the influence of phonological well-formedness of a word onto participants' rating of its goodness will be examined and controlled for in a more systematic way.

\subsubsection{The wug test: Elicited production and goodness judgment}

This section reports the results from both elicited productions and goodness judgments. Here we consider only overall patterns of the results, providing a somewhat informal comparison between uni- and bi-directional models. In the next section, we provide a statistical analysis of the results, focusing on those of the goodness judgment task.

The forward formation test results are summarized in Table $2 .{ }^{10}$ All of the socalled 'irregular' alternation classes are clearly less productive, both in terms of the proportion of elicited forms and also the mean goodness ratings scores. For the $\mathrm{w}$-final stimuli, participants produced $75 \mathrm{u}$-final forms $(34 \%)$ and assigned a mean goodness score of 5.54 to u-final outputs, whereas they produced $28 \mathrm{p}$ final forms $(13 \%)$ and assigned a mean score of 4.16 to p-final outputs. Thus, it can be said that the $\mathrm{w} \sim \mathrm{u}$ class of verbs is more productive than the $\mathrm{w} \sim \mathrm{p}$ class. For the 1-final stimuli, participants produced 1301 -final forms (59\%) and assigned a mean goodness rating of 5.67 to 1-final outputs, whereas they produced only

[10] Some participants produced two distinct forms for the same stimulus in the elicited production portion of the experiment. In those cases, we counted only the second form in the above presentation of the experimental results, ignoring the first one. Choosing the first form or both forms would not have changed the overall conclusion. 


\begin{tabular}{lcccc}
\hline $\begin{array}{l}\text { (a) Stimulus }=\text { w-final } \\
(\text { e.g. niw-ə) }\end{array}$ & $\begin{array}{c}\text { u-final } \\
(\text { niu-ca })\end{array}$ & $\begin{array}{c}\text { p-final } \\
(\text { nip-ca })\end{array}$ & $\begin{array}{c}\varnothing \text {-final } \\
(\text { ni-ca })\end{array}$ & Other \\
\hline $\begin{array}{l}\text { Percent (number) of elicited forms } \\
\text { (total: 220, 10 stimuli } \times 22 \text { participants })\end{array}$ & $\begin{array}{c}34 \% \\
(75)\end{array}$ & $\begin{array}{c}13 \% \\
(28)\end{array}$ & $\begin{array}{c}35 \% \\
(78)\end{array}$ & $\begin{array}{c}18 \% \\
(39)\end{array}$ \\
\hline Mean rating & 5.54 & 4.16 & Not tested & \\
\hline
\end{tabular}

\begin{tabular}{lccccc}
\hline $\begin{array}{l}\text { (b) Stimulus = 1-final } \\
\text { (e.g. kjəl-ə) }\end{array}$ & $\begin{array}{c}\text { 1-final } \\
\text { (kjəl-ca) }\end{array}$ & $\begin{array}{c}\text { t-final } \\
\text { (kjot-ca) }\end{array}$ & $\begin{array}{c}\text { li-final } \\
\text { (kjəli-ca) }\end{array}$ & $\begin{array}{c}\varnothing \text {-final } \\
\text { (kjo-ca) }\end{array}$ & Other \\
\hline $\begin{array}{l}\text { Percent (number) of elicited } \\
\text { forms (total: 220) }\end{array}$ & $\begin{array}{c}59 \% \\
(130)\end{array}$ & $\begin{array}{c}1 \% \\
(3)\end{array}$ & $\begin{array}{c}16 \% \\
(36)\end{array}$ & $\begin{array}{c}10 \% \\
(22)\end{array}$ & $\begin{array}{c}13 \% \\
(29)\end{array}$ \\
\hline Mean rating & 5.67 & 3.61 & Not tested & Not tested & \\
\hline
\end{tabular}

Note: 'Other' refers to errors elsewhere in the verb, and uninterpretable responses.

Table 2

Wug test results: forward formation.

three $t$-final forms $(1 \%)$ and assigned a mean score of 3.61 to $t$-final outputs. This suggests that the $1 \sim 1$ (non-alternating 1) class of verbs is more productive than the $1 \sim t$ class. Finally, the productions contained a considerable number of outputs that were completely unexpected, because they do not mirror any existing alternations. This included $78 \mathrm{w}$-deletion responses (35\%) for the w-final stimuli and 36 li-final ones (16\%) for the l-final stimuli. These relatively frequent but unexpected results will be discussed in Section 5 .

The backward formation test results are summarized in Table 3. As above, the 'irregular' patterns of alternation are clearly less productive, both in terms of the proportion of elicited forms and in terms of mean goodness ratings. For pfinal stimuli, participants produced $184 \mathrm{p}$-final forms (92\%) and assigned a mean goodness rating of 6.12 to $\mathrm{p}$-final forms, whereas they produced only four $\mathrm{w}$-final forms (2\%) and assigned a mean score of 3.92 to w-final forms. Thus, the nonalternating $p \sim p$ class of verbs is more productive than the $w \sim p$ class. For t-final stimuli, [c, t, s]-final responses are frequent in the elicited production portion and received relatively high goodness scores, compared to $[\varnothing, 1]$-final forms. Thus, it can be said that the $c \sim t, t \sim t$, and $s \sim t$ classes of verbs are more productive than the $\varnothing \sim \mathrm{t}$ and $1 \sim \mathrm{t}$ classes.

Taken together, these results show that the same alternations are productive regardless of the direction of the wug test. The highly productive group includes the $\mathrm{w} \sim \mathrm{u}, \mathrm{p} \sim \mathrm{p}, 1 \sim 1, \mathrm{c} \sim \mathrm{t}, \mathrm{t} \sim \mathrm{t}$, and $\mathrm{s} \sim \mathrm{t}$ classes, whereas the relatively unproductive group includes the $\mathrm{w} \sim \mathrm{p}, 1 \sim \mathrm{t}, \varnothing \sim \mathrm{t}$, and $1 \sim \mathrm{t}$ classes. 
(a) Stimulus $=$ p-final (e.g. nip-ca) p-final w-final $\mathrm{p}^{\mathrm{h}}$-final Other (nip-ə) (niw-ə) $\quad\left(\right.$ nip $^{\mathrm{h}}-$-ə)

\begin{tabular}{lcccc}
\hline $\begin{array}{l}\text { Percent (number) of elicited forms } \\
\text { (total: } 200,10 \text { stimuli } \times 20 \text { participants) }\end{array}$ & $\begin{array}{c}92 \% \\
(184)\end{array}$ & $\begin{array}{c}2 \% \\
(4)\end{array}$ & $\begin{array}{l}3 \% \\
(6)\end{array}$ & $\begin{array}{l}3 \% \\
(7)\end{array}$ \\
\hline Mean rating & 6.12 & 3.92 & Not tested
\end{tabular}

(b) Stimulus $=\mathrm{t}$-final c-final t-final s-final $\varnothing$-final l-final $\mathrm{t}^{\mathrm{h}}$-final Other

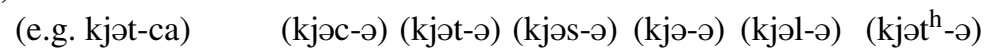

\begin{tabular}{lccccccc}
\hline $\begin{array}{l}\text { Percent (number) of } \\
\text { elicited forms } \\
\text { (total: 200) }\end{array}$ & $\begin{array}{r}29 \% \\
(58)\end{array}$ & $\begin{array}{r}21 \% \\
(41)\end{array}$ & $\begin{array}{c}28 \% \\
(55)\end{array}$ & $\begin{array}{c}3 \% \\
(5)\end{array}$ & $\begin{array}{c}4 \% \\
(7)\end{array}$ & $\begin{array}{c}4 \% \\
(7)\end{array}$ & $\begin{array}{l}14 \% \\
(27)\end{array}$ \\
\hline Mean rating & 5.04 & 5.02 & 4.73 & 3.11 & 2.97 & Not tested & \\
\hline
\end{tabular}

Note: 'Other' refers to errors elsewhere in the verb, and uninterpretable responses.

Table 3

Wug test results: backward formation.

The results in Table 3 show that the distribution of elicited forms and the mean goodness ratings scores in the backward formation test are not consistent with the predictions of the bi-directional model. Recall that under the bi-directional model, we expect asymmetries in the production of alternations, due to differences in the reliability of forward formation rules and their backward formation counterparts. Specifically, we showed in Section 1.2.1 that the backward formation rules for coronal-final verb stems in Seoul Korean tend to have low reliability/confidence values. This is due to the fact that stem-final coronal obstruents are neutralized to [t] before $\mathrm{C}$-initial suffixes, so the pre- $\mathrm{V}$ realization of a given stem is unpredictable. Nonetheless, participants frequently produced [c, t, s]-final forms, and gave such outputs high ratings. This is unexpected, if speakers were using backward formation rules, since those rules should have low confidence. In contrast, the results are consistent with a uni-directional model in which only forward formation rules are available. Recall that the forward formation rules for the $s \sim t$ and $t \sim t$ alternation class verbs in (11a.iv $-v)$ have relatively high confidence values (0.872 and 0.916 , respectively), so these alternations are predicted to be highly productive. The confidence value for the $\mathrm{c} \sim \mathrm{t}$ alternation class is not generally as high; for instance, rule (11a.vi) has a confidence score of 0.423 . However, as discussed in Section 1.2.1, island of reliability effects may play a role here. Recall that the $c \sim t$ alternation is dominant in the post-[i] context (7/8 verbs), and thus the relevant forward formation rule in (11a.vii) has a high confidence value of 0.740 . Among ten t-final wug verb stimuli adopted in the backward 
formation test, three verbs end with [it]. As shown below, their c-final class forms received high goodness scores (mean $=6.0$ out of 7.0 ), compared to those of the rest of the t-final stimuli.

(18) Goodness ratings of c-final forms (backward formation test)

$\begin{array}{lll}\text { STEM-FINAL VOWEL } & \text { NUMBER OF VERBS } & \text { AVERAGE } \\ \text { [i] } & 3 & 6.0 \\ \text { Other than [i] } & 7 & 4.6\end{array}$

It is obvious that the c $\sim$ alternation was not applied evenly across all /t/-final wug stems, but rather, was favored specifically for the three verbs with a preceding /i/. Thus, once we take detailed rule contexts into account, the confidence values of forward formation rules can explain much of why $\mathrm{c} \sim \mathrm{t}$ alternations enjoyed a modest degree of productivity. In conclusion, the overall pattern of results is consistent with the predictions of the uni-directional model. In the next section, we provide a more systematic evaluation of possible accounts of the test results.

\section{Discussion}

In this section, we provide a more detailed comparison of the predictions of the bi- and uni-directional models.

\subsection{Word-by-word comparison}

In order to test how closely participants' responses mirror the probability of alternation in the lexicon, we calculated predicted scores for all of the test items. We trained the minimal generalization model on the lexicon of Seoul Korean, in both the forward and backward formation directions, and used the resulting grammar to derive predicted scores for each candidate output for the test items. As discussed above, the minimal generalization model usually induces multiples rules that could all apply to a given form to produce the same change or alternation. We assume that from the set of potentially applicable rules, the best rule, i.e. the one with highest confidence, is chosen to apply, and determines the goodness of the alternation. As a result, we have provided a single confidence for each of the test forms employed in the wug test. However, it can also happen that there are no rules that can apply to a given form to produce a particular alternation. This happens because the minimal generalization learner, as described above, constructs the most specific rules possible. Consequently, if all of the existing words that undergo a particular alternation share certain properties, the resulting rules will also share those properties. In such cases, the alternation is predicted to be inapplicable to nonce words that do not share the relevant properties. For instance, all existing $w \sim p$ alternating stems have [-low] final vowels, so test forms with stem-final [+low] vowels, such as [golaw] and [golap], do not meet the structural description of the rules for the $w \sim p$ alternation. In such cases, we 
assigned a predicted confidence score of zero to the relevant test forms. For all the inflected forms employed in the goodness ratings task of the current wug test, confidence values of the best forward and backward formation rules are provided in Appendix B, alongside the mean goodness ratings.

In order to evaluate how well different sets of rules can explain wug test results, we will compare the rules' confidence values with the mean goodness ratings of the test forms. If goodness ratings scores vary proportionately with the confidence values, the relevant rules would be considered as a good predictor of the test results. The following shows the correlations of goodness scores to confidence values of the forward and backward formation rules:

\section{Correlations between goodness ratings and confidence values}

\section{DIRECTION OF WUG TEST DIRECTION OF RULES}

(a) Forward

(b) Backward

(c) Backward
Forward

Backward

Forward
CORRELATION

$$
r(40)=0.915
$$$$
r(70)=0.747
$$

$r(70)=0.810$

For the forward wug test, participants' goodness ratings show a strong positive correlation with the confidence scores of the forward formation rules. This shows that in the forward direction, speakers are sensitive to the same statistical trends in the lexicon that are encoded by probabilistic grammar induced by the minimal generalization model. We therefore reject models based solely on random guessing or paradigm uniformity, in favor of a model that tracks at least some lexical statistics concerning the relative frequency of different alternations.

The comparison between (19b) and (19c) above shows that participants' ratings do not reflect all lexical statistics, however. Crucially, in the backward formation task, participant ratings do not correlate as strongly with the predictions of the backward formation rules; instead, they correlate more strongly with the confidence of forward formation rules. In other words, the best model of speakers' judgments is one that contains only forward formation rules, and no backward formation rules. This supports the uni-directional model over the bi-directional model.

Before we proceed to a more detailed comparison of the uni- and bi-directional models, let us consider exactly which aspects of the results of the backward formation test can be better explained by the forward formation rules. As can be seen in Appendix B.2, cases where forward and backward formation rules have distinct confidence values involve $[\mathrm{p}, \mathrm{t}, \mathrm{s}, \mathrm{c}]$-final response forms which correspond to the $\mathrm{p} \sim \mathrm{p}, \mathrm{t} \sim \mathrm{t}, \mathrm{s} \sim \mathrm{t}$ and $\mathrm{c} \sim \mathrm{t}$ (non-)alternating classes, respectively. For these cases, forward formation rules have significantly higher confidence values than their backward formation counterpart rules. (Recall the relevant discussion about the rules for the $s \sim t$ alternating class in Section 1.2 above.) The relatively higher confidence values of the forward formation rules provide a better match to the high goodness scores given to the test forms of the $\mathrm{p} \sim \mathrm{p}, \mathrm{t} \sim \mathrm{t}, \mathrm{s} \sim \mathrm{t}$ and $\mathrm{c} \sim \mathrm{t}$ 
classes. In sum, the productivity of the $\mathrm{p} \sim \mathrm{p}, \mathrm{t} \sim \mathrm{t}, \mathrm{s} \sim \mathrm{t}$ and $\mathrm{c} \sim \mathrm{t}$ classes is predicted by the forward formation, but not the backward formation rules.

\subsection{Mixed effects analysis}

Thus far, we have considered only mean ratings scores, abstracting away from differences of individual participants. In this section, for a more stringent test, we take into consideration individual participant (and item) differences. The results of the present wug test were fitted with the lmer function from the lme4 package (Bates, Maechler \& Bolker 2011) in R (R Development Core Team 2014). Specifically, we provide a mixed effects analysis, taking the goodness rating of the inflected form as the dependent variable, confidence values, phonological wellformedness ratings and the final segment type of the stem (coronal vs. labial) as fixed factors, and participants and wug stems as random factors.

\subsubsection{Results of the forward formation test}

The mixed effects analysis of goodness ratings in the forward formation test shows significant effects of both random and fixed factors. Specifically, as can be seen in Table 4, the random effects for this model shows that there are fairly large estimates given to the slopes for confidence values of forward formation rules, labeled as 'forward confidence', with participant, labeled as 'participant', and test verb stem, labeled as 'verb', meaning that different participants and wug verb stems show greater/lesser effects of the model's confidence score.

\begin{tabular}{llll}
\hline Groups & Name & Variance & SD \\
\hline Participant & (Intercept) & 2.00 & 1.42 \\
& Normalized stem rating (participant-specific) & 0.00 & 0.07 \\
& Normalized stem rating (mean across participants) & 0.02 & 0.14 \\
& Forward confidence & 2.38 & 1.54 \\
& Stem-final segment type & 0.16 & 0.40 \\
\multirow{4}{*}{ Verb } & (Intercept) & 0.29 & 0.54 \\
& Normalized stem rating (participant-specific) & 0.01 & 0.10 \\
& Normalized stem rating (mean across participants) & 0.15 & 0.38 \\
& Forward confidence & 0.57 & 0.75 \\
& Stem-final segment type & 0.22 & 0.47 \\
\multirow{2}{*}{ Residual } & & 1.24 & 1.11 \\
\hline
\end{tabular}

Note: Number of observations: 880. Groups: participant, 22; verb, 20.

Table 4

Random effects: forward-forward comparison. 


\begin{tabular}{lrrr}
\hline Factor & Estimate & SE & $t$-value \\
\hline (Intercept) & 3.38 & 0.34 & 9.98 \\
Normalized stem rating (participant-specific) & -0.01 & 0.05 & -0.11 \\
Normalized stem rating (mean across participants) & 0.20 & 0.16 & 1.24 \\
Forward confidence & 2.63 & 0.39 & 6.75 \\
Stem-final segment type & 0.09 & 0.17 & 0.54 \\
\hline
\end{tabular}

Table 5

Fixed effects: forward-forward comparison.

Even once these random factors are taken into account, as can be seen in Table 5, the confidence values of forward formation rules still have a sizable effect on the goodness ratings $(t=6.75)$, which holds independently of the specific participant.

In contrast, phonological well-formedness factors - including both stem wellformedness ratings normalized by participant and averaged across all participants - have a very weak effect on the goodness ratings $(t=-0.11,1.24)$. This analysis suggests that participants' ratings are due to knowledge of the relative probability of different alternations in the lexicon, as encoded by the forward formation rules' confidences. This result is consistent with both the uni- and bi-directional models, since both posit rules relating base forms to non-base forms. The next section concerns predictions of the two models with respect to the backward formation test results.

\subsubsection{Results of the backward formation test}

To find out whether results of the backward formation test are more consistent with the predictions of the backward or forward formation rules, we constructed two mixed effects models, one with backward confidence (confidence values provided by backward formation rules) as a fixed factor (which we will call 'backward only' model) and the other with forward confidence as a fixed factor (which we will call 'forward only' model). As can be seen in Tables 6 and 7, just like the mixed effect model presented in the previous section, both of these models show the confidence's sizable effect on the goodness ratings $(t=10.90$, 10.43), which holds independently of the specific participant.

This means that participants' ratings are significantly correlated with the confidence values of both the forward and backward formation rules. This is not surprising, given the positive correlations seen in the previous section, and the fact that the confidence scores in the two directions are often correlated with each other. The question, then, is whether one set of rules provides a better model than the other. We then compared the log likelihood and the Akaike Information Criterion (AIC) values of the two models in order to determine which model provides a better fit to the goodness ratings data. As shown in Table 8, the log 
likelihood ( $\log L i k)$ for the 'forward-only' model is higher (better fit), and the AIC value is lower (again, better fit).

\begin{tabular}{lrrr}
\hline Factor & Estimate & SE & $t$-value \\
\hline (Intercept) & 3.26 & 0.28 & 11.60 \\
Normalized stem rating (participant-specific) & -0.02 & 0.05 & -0.30 \\
Normalized stem rating (mean across participants) & 0.02 & 0.10 & 0.18 \\
Backward Confidence & 5.25 & 0.48 & 10.90 \\
Stem-final segment type & -0.28 & 0.22 & -1.26 \\
\hline
\end{tabular}

Table 6

Fixed effects: 'backward only' model.

\begin{tabular}{lrrr}
\hline Factor & Estimate & SE & $t$-value \\
\hline (Intercept) & 3.51 & 0.27 & 13.19 \\
Normalized stem rating (participant-specific) & -0.01 & 0.05 & -0.20 \\
Normalized stem rating (mean across participants) & -0.07 & 0.14 & -0.48 \\
Forward Confidence & 2.76 & 0.27 & 10.43 \\
Stem-final segment type & -0.95 & 0.23 & -4.12 \\
\hline
\end{tabular}

Table 7

Fixed effects: 'forward only' model.

\begin{tabular}{lccccc}
\hline Model & AIC & BIC & logLik & Deviance & REMLdev \\
\hline Forward-only & 4912 & 5048 & -2430 & 4860 & 1374 \\
Backward-only & 5134 & 5270 & -2541 & 5082 & 1374 \\
\hline
\end{tabular}

Table 8

Model comparison: 'forward-only' vs. 'backward-only'.

This model comparison confirms that participant ratings in the backward formation test are better modeled using the confidence scores of forward formation rules than backward formation rules. This interpretation is confirmed by a correlation test between participants' goodness ratings of the backward formation test and the predicted values of the models. The test shows that the predicted values of 'forward-only' model $\left(\mathrm{R}^{2}=0.764\right)$ are correlated more strongly with the goodness ratings of the backward formation test, compared to those of 'backwardonly' model $\left(\mathrm{R}^{2}=0.711\right)$.

We therefore conclude that the 'forward-only' model provides a more accurate account of the ratings data than the 'backward-only' model. Consequently, the 
mixed effects analyses presented above provide support for the uni-directional model over the bi-directional model.

\section{Alternatives}

In the previous section, we discussed how well the bi- and uni-directional models explain the results of the wug test, focusing on the backward formation test. In this section, we consider other possible accounts.

\subsection{Generality of phonological processes}

As reported in Section 2.4.2 above, participant productions and goodness ratings indicate that a particular set of (non-)alternation classes is productive, regardless of the direction of the wug test. The high productive group includes the $w \sim u, p \sim p$, $1 \sim 1, \mathrm{c} \sim \mathrm{t}, \mathrm{t} \sim \mathrm{t}$, and $\mathrm{s} \sim \mathrm{t}$ classes, whereas the low productive group includes the $\mathrm{w} \sim \mathrm{p}, 1 \sim \mathrm{t}$, $\varnothing \sim \mathrm{t}$, and $1 \sim \mathrm{t}$ classes.

In order to explain the observed difference in productivity between the two groups, one might consider the possibility that the alternations of the high productive classes are phonologically more predictable than those of low productive ones. Note that the alternations of the high productive classes are the result of applying automatic phonological processes such as coda neutralization and glide formation. In contrast, if we follow the traditional phonological analyses, mentioned in Section 1.1, the alternations of the low productive classes would be the result of applying lenition processes with exceptions, which have been called 'irregular' processes.

Note, however, that there are many other alternation classes which are due to the same automatic processes, but nonetheless show low productivity. Note that the $\mathrm{c}^{\mathrm{h}} \sim \mathrm{t}, \mathrm{t}^{\mathrm{h}} \sim \mathrm{t}$, and $\mathrm{p}^{\mathrm{h}} \sim \mathrm{p}$ alternation class verbs, like the highly productive $\mathrm{w} \sim \mathrm{u}, \mathrm{p} \sim \mathrm{p}, 1 \sim 1, \mathrm{c} \sim \mathrm{t}, \mathrm{t} \sim \mathrm{t}$, and $\mathrm{s} \sim \mathrm{t}$ classes, involve the automatic process of coda neutralization. Nonetheless, inflected forms involving these alternations were rarely chosen by the experiment participants, as can be seen in the results of elicited production reported in Table 3 above. Thus, we cannot simply attribute the observed differences in productivity to the generality of the phonological processes involved in their alternations.

\subsection{Influence from the noun lexicon}

As discussed in Section 2.4.2, one prominent pattern of the backward formation test results which is not consistent with the predictions of backward formation rules is the frequent occurrence and high ratings of s-final forms. The productivity of $s \sim t$ alternations is interesting, because verbs with $s \sim t$ alternations are greatly outnumbered by verbs with other alternations (e.g. $t \sim t$ and $t \sim c$ ) in Seoul Korean. We have attributed this productivity to the fact that in the forward direction, pre$\mathrm{V} / \mathrm{s} /$ does consistently correspond with pre-C / $/$ / . However, another possibility 
that must be considered is that $s \sim t$ alternations in verbs are encouraged by their prevalence in noun paradigms. In Seoul Korean noun paradigms, stem-final /s/ is very frequent among coronal-final stems. It has been pointed out in the literature on Korean phonology and morphology (Ko 1989; Hayes 1998; Albright 2002a, 2005; Kang 2003; Jun 2010 among others) that /s/ is in fact the most frequent stem-final coronal obstruent in nouns, as shown below, and it is thus adopted as an innovative variant among nouns with stem-final coronal obstruents, for instance /pat ${ }^{\mathrm{h}}$-ill [pat $\left.{ }^{\mathrm{h}} \dot{\mathrm{il}}\right]$ [pasil] 'field (ACC)'.

(20) Distribution of stem-final coronal obstruents of Korean nouns (from Jun 2010: 149)

$\begin{array}{lr}\mathrm{t} & 2 \\ \mathrm{t}^{\mathrm{h}} & 116 \\ \mathrm{t} & 0 \\ \mathrm{c} & 18 \\ \mathrm{c}^{\mathrm{h}} & 164 \\ \mathrm{c}^{\prime} & 0 \\ \mathrm{~s} & 308 \\ \mathrm{~s}, & 0\end{array}$

In the experiment, wug stems were placed in frames where only verbs can appear, so this result could not be due to misanalysis of the wug items as nouns. However, one might still consider the possibility that the observed high productivity of s-final forms is due to the influence of the noun lexicon. If the participants considered not only the verb lexicon but also the noun lexicon in the test, they are expected to produce s-final forms as frequently as they did in the test since a large number of nouns with final /s/ would contribute to the reliability/confidence of backward formation rules deriving s-final forms.

We consider this possibility quite unlikely for the following two reasons. First, as can be seen in (20), stem-final $/ \mathrm{c}^{\mathrm{h}} /$ is also frequent in the noun lexicon, and this frequent occurrence of stem-final $/ \mathrm{c}^{\mathrm{h}} /$ has been adopted as the basis for the occurrence of innovative forms involving them (Jun 2010): for instance, /mit ${ }^{\mathrm{h}}-\mathrm{il} /$ [mit $\left.{ }^{\mathrm{h}} \dot{\mathrm{il}}\right]$ [mic $\left.{ }^{\mathrm{h}} \mathrm{il}\right]$ 'bottom (ACC)'. Thus, if the participants were influenced by lexical frequencies of alternations among nouns, $\mathrm{c}^{\mathrm{h}}$-final forms should be expected to be at least partly productive. However, in the production test, participants never volunteered $\mathrm{c}^{\mathrm{h}}$-final forms. This low productivity of $\mathrm{c}^{\mathrm{h}}$-final forms undermines the possibility that the noun lexicon was considered by the participants of the current wug test.

More importantly, if alternations among nonce verbs are influenced by other lexical categories, we would expect adjectives to play a role as well. In fact, because verbs and adjectives have a great deal of morphological overlap in Korean, it is controversial whether the two even belong to separate categories. The distinction between the two is mainly based on restrictions on a couple of 
suffixes such as -(ni)n 'non-past indicative' that can be attached only to verb stems, not adjectives (Sohn 1999, Mok 2003). Since the category distinction between verbs and adjectives in Korean is at best weak, we might expect lexical statistics of alternations among adjectives to influence responses at least as much as nouns. The results of the present experiment show no such indication. Note below that the $\mathrm{w} \sim \mathrm{p}$ alternation class is much more frequent than the $\mathrm{p} \sim \mathrm{p}$ class in the adjective lexicon, and thus even after combining verbs and adjectives, the $\mathrm{w} \sim \mathrm{p}$ class is still dominant. ${ }^{11}$ If both verbs and adjectives contribute to the rule reliability/confidence, the rule for the $w \sim p$ alternation should have very high reliability/confidence, predicting high productivity of the $\mathrm{w} \sim \mathrm{p}$ class forms. This is not what we found; instead, $w \sim p$ alternations are dispreferred, consistent with their low frequency in the verb lexicon.

\section{(21)}

Lexical frequencies of the $p \sim p$ and $w \sim p$ (non-)alternation verbs and adjectives

$\begin{array}{lccc}\text { (NON-)ALTERNATION } & \text { VERB } & \text { ADJECTIVE } & \text { VERB + ADJECTIVE } \\ \mathrm{p} \sim \mathrm{p} & 13 & 3 & 16 \\ \mathrm{~W} \sim \mathrm{p} & 6 & 61 & 67\end{array}$

Thus, we conclude that the high degree of productivity for $\mathrm{s} \sim \mathrm{t}$ alternations should be attributed to the high confidence of forward $\mathrm{s} \rightarrow \mathrm{t}$ rules, and not to the independent existence of $\mathrm{t} \sim \mathrm{s}$ alternations in nouns.

\subsection{Paradigm uniformity and Bayes' theorem}

In Section 3, we showed that although the forward formation test results are consistent with the predictions of the forward formation rules, the backward formation test results are not so consistent with the predictions of the backward formation rules. This is problematic for the bi-directional model of inferring alternations. We also showed that the backward formation test results are better explained by the forward formation rules than the backward formation rules. This helps support the uni-directional model, which includes only forward formation rules. In this section, we discuss some other mechanisms that have the potential to explain the backward formation test results.

Let us first consider the possibility that results of the backward formation test are due to paradigm uniformity. Recall from Section 1.2.2, this option makes more sense under the single base hypothesis, since such asymmetrical models have a ready-made explanation for why speakers would use different strategies in different directions. As shown below, the strongly favored $[\mathrm{p}, \mathrm{t}]$-final responses are almost identical to the $\mathrm{p}$, $\mathrm{t}$-final stimuli (except for allophonic voicing, not shown

[11] To obtain the lexical frequency of these adjective classes, we adopted the same procedure as we did for the lexical frequency of verb classes, described in Section 1.2.1 above. 
in the phonetic transcription of this paper). Thus, these forms satisfy paradigm uniformity, and could potentially be favored by paradigm uniformity constraints.

Paradigm uniformity in backward formation ([p, $t]$-final stimuli)

Test results: $[\mathrm{p}, \mathrm{t}, \mathrm{s}, \mathrm{c}]$-final $=$ high $\left(\right.$ in productivity); $\left[\mathrm{w}, \mathrm{s}, \mathrm{t}^{\mathrm{h}}, \varnothing\right]$-final $=$ low.

\begin{tabular}{|c|c|c|c|}
\hline \multirow[t]{2}{*}{ Stimulus } & & \multicolumn{2}{|r|}{ Response } \\
\hline & & High & Low \\
\hline i. p-final & e.g. [nip-c'a] & $\approx$ [nip-ə] & $\neq[$ niw-ə] \\
\hline \multirow[t]{3}{*}{ ii. t-final } & e.g. [kjət-c'a] & $\approx[$ kjət-ə] & $\neq=[\mathrm{kj} \partial \mathbf{r}-\partial],\left[\mathrm{kj}^{2} \mathbf{t}^{\mathbf{h}}-\partial\right]$ \\
\hline & & $\neq[$ kjəc-ə] & \\
\hline & & $\neq[$ kjəs-ə] & $\neq[\mathrm{kj} ə-ə]$ \\
\hline
\end{tabular}

Paradigm uniformity cannot explain the high productivity of $s \sim \mathrm{t}$ and $\mathrm{c} \sim \mathrm{t}$ alternations, however. For t-final stimuli, paradigm uniformity unequivocally favors $\left[\mathrm{r}, \mathrm{t}^{\mathrm{h}}\right]$-final outputs over [s, c]-final outputs. Thus, we find that paradigm uniformity is not a good predictor of participant responses, in either the forward or backward direction. (See Coetzee 2009 for the claim that paradigm uniformity is the default option, if other things, including lexical frequency, are equal.)

As suggested by an anonymous referee, another possible option under the single base hypothesis is use of forward formation rules, together with Bayes' Theorem, in the explanation of the backward formation test results. Bayes' theorem is typically used for deriving a conditional probability from its reverse conditional probability: $\mathrm{P}(\mathrm{x} \mid \mathrm{y})=\mathrm{P}(\mathrm{y} \mid \mathrm{x}) * \mathrm{P}(\mathrm{x}) / \mathrm{P}(\mathrm{y})$. Thus, if we know only the confidence of forward formation rules, which can be considered as the conditional probability of having a pre- $\mathrm{C}$ form given its corresponding pre- $\mathrm{V}$ form, we would be able to derive, through Bayes' theorem, the confidence of backward formation rules, i.e. the conditional probability of having a pre- $\mathrm{V}$ form given its corresponding pre-C form. However, the resulting model's prediction about the results of the wug test would be no different from that of the bi-directional model since the two models' predictions are based on the same set of confidence values. As shown in the previous section, the bi-directional model does not provide a satisfactory explanation of the results of the backward formation test; thus, a model based on Bayes' theorem does not intrinsically solve the problem of how to invert forward formation rules to apply them in backward formations.

\subsection{A superset model with both forward and backward confidence}

In Section 3, we compared a grammar containing rules in only one direction (base $\rightarrow$ derived) with a grammar that contains different rules for each direction of derivation (base $\rightarrow$ derived, and derived $\rightarrow$ base). In order to test which 
grammar provides a better account of the current wug test results, we constructed two mixed effects models: 'forward-only' and 'backward-only'. These models include, as fixed factors, confidence values provided by forward formation rules (forward confidence) and those provided by backward formation rules (backward confidence), respectively. It was shown that the 'forward-only' model provides a more accurate account of the ratings data of the backward formation test than the 'backward-only' model. This provides support for the hypothesis that grammars contain rules in only one direction, and speakers use these rules 'in reverse' to do backward formation, when necessary.

An alternative possibility, suggested by an anonymous referee, is that grammars contain rules in both directions, and that speakers can access both simultaneously. In order to test this possibility, we constructed a superset model with both sets of confidence values (provided by forward and backward formation rules), as fixed factors. As can be seen in Table 9, this superset mixed effects model shows that the forward and backward confidence values both have a noticeable effect on the goodness ratings of the backward formation test, which holds independently of the specific participant.

\begin{tabular}{lrrr}
\hline Factor & Estimate & SE & $t$-value \\
\hline (Intercept) & 3.04 & 0.29 & 10.54 \\
Normalized stem rating (participant-specific) & -0.02 & 0.04 & -0.36 \\
Normalized stem rating (mean across participants) & -0.01 & 0.14 & -0.07 \\
Forward Confidence & 2.37 & 0.39 & 6.12 \\
Backward Confidence & 1.49 & 0.75 & 1.98 \\
Stem-final segment type & -0.58 & 0.23 & -2.53 \\
\hline
\end{tabular}

Table 9

Fixed effects: a superset model.

We did a likelihood ratio test on the nested comparison of this superset model and the 'forward-only' model. The result shows that the superset model is significantly better $(p<.001)$ than the 'forward-only' model, indicating that the backward confidence values explain some variance in the ratings that the forward confidence values do not.

This result appears to support a model in which speakers have simultaneous access to rules in both directions. However, crucially, they do not support a symmetrical bi-directional model, in which rules in all directions have equal status. Recall from Section 3.2.2 that a model with forward confidence values provided a better account of the ratings data in the backward formation test than backward confidence values; that is, even if both play some role in predicting ratings in the backward formation test, the forward confidence rules are the primary determinant. This asymmetry is also seen clearly in the magnitudes of the coefficients for the two predictors in Table 9. As mentioned in Section 1.2.2, 
under a relaxed version of a single base hypothesis, backward formation rules may exist, but are limited in their application in some way. Given that the base form has a privileged status, it is expected under this relaxed version of a single base hypothesis that forward formation rules would play a larger role in explaining the mapping in each direction. This expectation is consistent with the result of the statistical analyses presented above.

This result raises a deeper question about the role and status of 'backwards' direction rules: if speakers rely primarily on forward rules, why would the grammar additionally contain backward rules that are used simultaneously, but to a lesser extent? We can only offer tentative speculation on this point. One possibility is that the 'backward' effect, although significant, has a fundamentally different source than the 'forward' effect. For example, perhaps the grammar contains only forward rules, as in the single surface base hypothesis, but speakers also make recourse to non-grammatical analogical comparisons when they are forced to use the rules in reverse to do backward (derived $\rightarrow$ base) derivations. Alternatively, perhaps the grammar does contain rules in both directions, as suggested by the relaxed version of the single surface base hypothesis, but the forward direction rules are 'privileged': speakers are more likely to use them, or trust them more, in cases where the outcomes conflict.

\section{REMAINING PUZZLES}

In Section 2.4.2, we reported two unexpected response patterns from the elicited production portion of the experiment. First, many responses for the w-final stimuli (e.g. [naluw-ə]) involve w-deletion (e.g. [nalu-ca]). Forms of this type (78 occurrences) were even more frequent than $\mathrm{u}$-final forms (75 occurrences). Second, for the l-final stimuli (e.g. [kjəl-ə]), 36 i-insertion forms (e.g. [kjəli-ca]) were produced. These two patterns were not expected to occur, and thus they were not even included in the goodness ratings task. We will first discuss the w-deletion and then $\mathrm{i}$-insertion forms.

There are two potential explanations for the frequent deletion of the stemfinal [w] attested in the current wug test: optional w-epenthesis and stem-final [u]-deletion. ${ }^{12}$ As mentioned above, stem-final $[\mathrm{u}]$ typically undergoes glide formation before $\mathrm{V}$-initial suffixes, but an additional hiatus-avoidance process is reported to occur variably $(\mathrm{Kim} 2000)$. [w] is sometimes inserted between the stem-final /u/ (and /o/) and the suffix-initial vowel, e.g. /katu-ə/ [katwə] [katuwə] 'block in (IMP)'. It may be the case that participants considered the stem-final [w] to be an epenthetic consonant, and thus they omitted it before C-initial suffixes (e.g. [nalu-ca]). This analysis is supported by the fact that for the two test stems

[12] We discovered this possibility while talking with Na-young Park. This part of the paper has greatly benefited from her wide range of knowledge of Korean glide formation and related phenomena. 
ending in the sequence [uw], [naluw-ə] and [nasuw-ə], more than half of the participants deleted [w] with the -ca suffix: 15 [nalu-ca] and 12 [nasu-ca].

The rest of [w]-deletion forms may be attributed to another optional process in which stem-final /u/ deletes in some Seoul Korean verbs, as shown in (23).

(23) Optional stem-final [u]-deletion in Seoul Korean (based on Kim 2000: 92)

(a) $/$ k'iu-ta/ $[$ k'iuta $] \sim$ [k'ita] 'put in'
(b) $/$ piu-ta/ $[$ piuta $] \sim$ [pita] 'empty'
(c) $/$ keu-ta/ $[$ keuta $] \sim$ [keta] 'throw up'

In Kim's (2000) description of this process, its application domain is not specifically limited to the pre-C context. But, insofar as this deletion can occur before C-initial suffixes, and Korean speakers are aware of it, it would not be surprising that the participants applied this deletion while responding to the [w]-final stimuli in the current experiment.

Consequently, the phonological processes of glide epenthesis and deletion may explain why speakers' productions frequently showed $\mathrm{w} \varnothing$ alternation. Both of these are relatively minor processes in Korean, and the details of their occurrence bear further investigation; however, the facts above are consistent with a phonological explanation for this unexpected pattern.

Let us now consider $\mathrm{i}$-insertion forms (e.g. [kjəli-ca]) for the l-final stimuli (e.g. [kjəl-ə]). Given that there are only six li-final verb stems with the $\varnothing \sim \mathrm{i}$ alternation in the Seoul Korean verb lexicon, forms of this type were not expected to be produced as often as they were. We think that this unexpected pattern can be attributed to the experimenter's careful articulation of the stimuli. Recall that a flap and a lateral are in an allophonic relationship in Korean, as shown below.

\section{(24) Allophones of the liquid phoneme in Korean}

$\begin{array}{rlllll}\text { (a) Flap: } & \text { a single onset } & \text { /tali/ } & \text { [tari] } & \text { 'leg' } \\ \text { (b) Lateral: i. } & \text { coda } & \text { /tal/ } & \text { [tal] } & \text { 'moon' } \\ & \text { ii. } & \text { geminate } & \text { /hollo/ } & \text { [hollo] } & \text { 'alone' }\end{array}$

A flap is allowed to occur only as a single onset, whereas a lateral may occur as a coda or a geminate. The stem-final /1/ of the l-final stimuli occurs between vowels, and thus it should be pronounced as a flap in Korean. However, during the experiment, the experimenter attempted to pronounce the stimuli clearly, in order to avoid segmental misperceptions. This attempt may occasionally have lead the experimenter to pronounce the morphemes separately, causing the $/ 1 /$ to be pronounced in the coda of the stem. This coda lateral may have been interpreted as a geminate by Korean listeners, since a pre-V lateral must be a geminate according to Korean phonotactics.

Stems with a geminate [1] before V-initial suffixes are mostly the ll li alternating verbs which have been called 'li-irregular' in the traditional literature: 


\section{Example verbs with the ll li alternation}

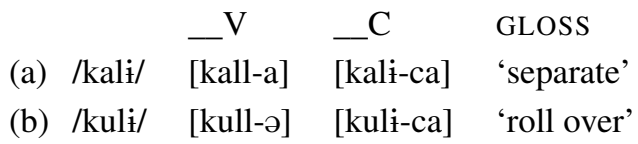

There are many verbs of this alternation type, 38 in the Seoul Korean verb lexicon adopted in the present study. If participants heard ///-final stimuli such as /kjəl-ə/ as involving a geminate lateral (e.g. [kjollə]), they would be very likely to produce ll li forms (e.g. [kjori-ca]).

The above explanations of the two unexpected response patterns are tentative, but consistent with the data. Crucially, whatever the best explanation for these outputs ultimately is, these unexpected patterns do not threaten to undermine our conclusions about bi- and uni-directional models, for the following reasons. First, the unexpected patterns were observed from results of the elicited production portion of the experiment, while most of the statistical tests presented here concern the goodness judgment task. In addition, the unexpected response patterns were confined to the forward formation test, about which both bi- and unidirectional models make the same predictions. Therefore, although it is true that the occurrence of those unexpected response patterns must be fully understood in order to obtain a final account of how Seoul Korean speakers apply the full range of alternations, we leave an in-depth investigation of them for future research.

\section{CONCLUSion}

In the present study, we have performed two-way wug tests on Seoul Korean verbal paradigms, in order to probe how speakers make inferences about unpredictable allomorph selection in unknown stems. We have considered several possible models of the inference about the allomorph selection, focusing on those relying on probabilistic rules that track lexical frequencies.

Adopting the minimal generalization learner, we have first constructed two sets of rules, those deriving non-base surface allomorphs of Seoul Korean verbs from their base forms (forward formation) and those responsible for the derivation of the opposite direction (backward formation). These rules are accompanied with reliability/confidence values, i.e. rule application probabilities, which are determined by the relevant lexical frequencies.

The results are broadly consistent with a model in which speakers infer alternations based on rules, rather than based on paradigm uniformity or random guessing. In addition, we find support for the hypothesis that grammar is asymmetrical, and speakers do not learn rules for all logically possible mappings. In particular, correlation tests and mixed effects analyses showed that the results of the backward formation test are more consistent with the prediction of the forward formation rules than that of the backward formation rules. This supports Albright's (2002a et seq.) single base hypothesis, where only forward formation rules are available. 


\section{APPENDIX A}

\section{Experiment procedure}

Two sheets for pen-and-paper tests were prepared to give instructions and collect responses: the first one is for tasks (i) and (ii), and the second for task (iii).

(A1) Tasks (repeated from example (13) in the text)

(i) Phonological well-formedness rating of the wug verb stimuli

(ii) Production of inflected forms of wug verbs

(iii) Goodness rating of possible inflected forms of wug verbs

The first sheet consisted of three parts, A, B and C shown in (27).

(A2) Test sheet one

Part A

You are going to hear extinct Middle Korean verbs. Rate these words on a scale from 1 ('very unnatural, impossible as a Modern Korean verb') to 7 ('completely natural as a Modern Korean verb') according to how natural their pronunciations are as Modern Korean verbs.

As illustrated below, after you hear two sentences, one interrogative and one declarative, containing a Middle Korean verb, provide an imperative sentence containing the same verb. Then, write down the naturalness score for the verb. Finally, provide a hortative sentence containing the same verb.

Part B (forward formation test)

\begin{tabular}{|c|c|c|}
\hline \multicolumn{2}{|c|}{ Experimental prompts } & \multirow{2}{*}{$\begin{array}{l}\text { Glosses (not shown in the test sheet) } \\
\text { 'who' 'do (INT)' }\end{array}$} \\
\hline i. nuka he? & (interrogative) & \\
\hline ii. $\mathrm{C}^{\mathrm{h}}$ əlsu-ka he. & (declarative) & 'proper name-NOM’'do (DECL)’ \\
\hline iii. $\mathrm{C}^{\mathrm{h}}$ əlsu-ja he! & (imperative) & 'proper name-VOC' 'do (IMP)' \\
\hline Score: & & \\
\hline iv. uli-to ha-ca! & (hortative) & 'we-too' 'do-HORT' \\
\hline
\end{tabular}

Part B (backward formation test)

Experimental sentences Glosses (not shown in the test sheet)

\begin{tabular}{|c|c|c|}
\hline i. nuka ha-ko is'-ə? & (interrogative) & 'who' 'do-PROG-INT' \\
\hline ii. C $\mathrm{C}^{\mathrm{h}}$ əlsu-ka ha-ko is'-ə. & (declarative) & 'proper name-NOM' 'do-PROG-DECL' \\
\hline iii. uli-to ha-ca! & (hortative) & 'we-too' 'do-HORT' \\
\hline Score: & & \\
\hline iv. $C^{\mathrm{h}}$ əlsu-ja he! & (imperative) & 'proper name-VOC' 'do (IMP)' \\
\hline
\end{tabular}


Part C (volunteering portion: five practice items plus 40 test items)

\begin{tabular}{|r|ll|l|l|}
\hline 1 & sum 'hide' & & \\
\hline 2 & s'o 'shoot' & & \\
\hline 3 & sakwe 'make friends' & & \\
\hline 4 & sujkili 'crouch' & & \\
\hline 5 & s'aho 'fight' & & \\
\hline 6 & & 26 & \\
\hline$\ldots$ & & $\ldots$ & \\
\hline 25 & & 45 & \\
\hline
\end{tabular}

Part A contains the instructions. The experimenter emphasized that participants should rate the naturalness of the verb form only based on the pronunciation, not potential meaning. It was also mentioned that there were no right or wrong answers. Part B is an illustration of the task. Part C is the section for recording participants' phonological well-formedness rating.

In this experiment, participants were required to perform the sentence completion task, for which each wug verb was embedded in a frame consisting of four sentences like those in part B in (A2). The first three sentences were designed to contain a completely identical form of the wug verb inflected with V-initial suffixes (forward formation test) or $\mathrm{C}$-initial ones (backward formation test), and the final sentence contains the wug verb inflected in an opposite way, i.e. with $\mathrm{C}$-initial suffixes (forward formation test) or $\mathrm{V}$-initial ones (backward formation test). Note that the interrogative, declarative and imperative markers are all segmentally identical, i.e. [ə]/[a] which is the V-initial suffix. The hortative and progressive markers are C-initial, i.e. [ca] and [ko is'], respectively.

As can be seen in Part B in (A2), the task was illustrated to the participants using the verb stem $h a$ 'do'. This verb stem is chosen not only because it is a representative Korean verb stem just like do in English, but also because it shows a lexically idiosyncratic alternation, ha+ə $\rightarrow$ he, which is not adopted for any other Korean verbs, and is thus unlikely to bias the participants towards particular responses involving any of target patterns in the test.

Part $\mathrm{C}$ began with a training period of five verbs, two Modern Korean and three Middle Korean. Their stem forms were written on the test sheet. After a brief training session with these words, the main test session started. For each wug verb, the experimenter uttered the first two sentences of the frame. After hearing them, the participants were asked to pronounce the third sentence of the frame aloud. Sometimes, the participants failed to provide the expected form of the given wug verb which is segmentally identical to the one in the first two sentences of the 
frame. Many of these failures suggest that the participants misheard the final segment of the wug stem, which is the crucial part of the present study: for instance, a t-final stimulus [kamjət-c'a] was heard as a k-final stem [kamjək-c'a]. In some, but not all, of those cases, the experimenter repeated the previous step while pronouncing the first two sentences of the frame slowly so that the participants can hear the wug verb accurately. The responses from the participants who did not produce the correct form of the wug verb in this step were ignored in the analysis. Then, participants wrote down their phonological naturalness ratings of the wug verb in the relevant slot of the test sheet. Finally, the participants pronounced the fourth sentence with the inflected form of the same wug verb. The experimenter transcribed responses for this final sentence of the frame. The entire session of this part was recorded for most participants (37 of 42), and the experimenter checked with the audio recordings when s/he was not sure about the responses. When it was still difficult to identify the stem-final segment of the inflected wug verb from the response even after checking the audio recording, the response was excluded.

After completing test sheet one, participants were given a second test sheet to perform the goodness ratings of possible inflected forms of wug verbs.

(A3) Test sheet two

\section{Part A}

You are going to hear two sentences, the first of which includes the imperative form of a Middle Korean verb, and the second of which includes the corresponding hortative form. Please rate the hortative form on a scale from 1 ('very bad, impossible as a hortative form of the given verb') to 7 ('very good as a hortative form of the given verb') according to how good the hortative form is in relation to the verb given in the imperative sentence. (These instructions are for forward formation test. If we switch between 'hortative' and 'imperative' in the above, the result would be the instruction for backward formation test.)

Part B (40 items in forward test; 70 items in backward formation test)

\begin{tabular}{|l|l|l|l|}
\hline 1 & & & \\
\hline 2 & & & \\
\hline$\ldots$ & & $\ldots$ & \\
\hline
\end{tabular}

The rest of the experiment procedure is described in Section 2.3. 
APPENDIX B

\section{Mean ratings and model confidence values}

(B1) Inflected forms employed in forward formation test

\begin{tabular}{|c|c|c|c|c|c|}
\hline & & MEAN & MEAN & & \\
\hline & & STEM & INFLECTED & FORWARD & BACKWARD \\
\hline STIMULUS & RESPONSE & RATING & RATING & CONFIDENCE & CONFIDENCE \\
\hline kolawə & $\mathrm{u}$ & 3.727 & 5.136 & 0.887 & 0.928 \\
\hline kolawə & $\mathrm{p}$ & 3.727 & 3.955 & 0.000 & 0.000 \\
\hline naluwə & $\mathrm{u}$ & 4.773 & 5.273 & 0.625 & 0.000 \\
\hline naluwə & $\mathrm{p}$ & 4.773 & 4.136 & 0.389 & 0.278 \\
\hline naliwə & $\mathrm{u}$ & 4.318 & 5.818 & 0.845 & 0.928 \\
\hline naliwə & $\mathrm{p}$ & 4.318 & 4.273 & 0.389 & 0.278 \\
\hline nasuwə & $\mathrm{u}$ & 3.727 & 5.227 & 0.625 & 0.000 \\
\hline nasuwə & $\mathrm{p}$ & 3.727 & 4.545 & 0.389 & 0.278 \\
\hline newว & $\mathrm{u}$ & 4.591 & 5.909 & 0.887 & 0.928 \\
\hline newə & $\mathrm{p}$ & 4.591 & 3.636 & 0.000 & 0.000 \\
\hline nəlewว & $\mathrm{u}$ & 3.864 & 5.409 & 0.887 & 0.928 \\
\hline nəlewว & $\mathrm{p}$ & 3.864 & 4.091 & 0.000 & 0.000 \\
\hline niwว & $\mathrm{u}$ & 4.227 & 6.000 & 0.845 & 0.928 \\
\hline niwə & $\mathrm{p}$ & 4.227 & 4.591 & 0.389 & 0.278 \\
\hline mesiwə & $\mathrm{u}$ & 4.136 & 5.500 & 0.845 & 0.928 \\
\hline mesiwə & $\mathrm{p}$ & 4.136 & 4.045 & 0.389 & 0.278 \\
\hline səwว & $\mathrm{u}$ & 4.682 & 5.409 & 0.887 & 0.928 \\
\hline səwə & $\mathrm{p}$ & 4.682 & 3.909 & 0.000 & 0.000 \\
\hline asawə & $\mathrm{u}$ & 4.136 & 5.682 & 0.887 & 0.928 \\
\hline asawə & $\mathrm{p}$ & 4.136 & 4.409 & 0.000 & 0.000 \\
\hline kamyələ & $\mathrm{t}$ & 3.364 & 3.318 & 0.085 & 0.163 \\
\hline kamyələ & 1 & 3.364 & 6.318 & 0.792 & 0.986 \\
\hline kyələ & $\mathrm{t}$ & 4.364 & 3.591 & 0.085 & 0.163 \\
\hline kyələ & 1 & 4.364 & 4.864 & 0.792 & 0.986 \\
\hline kucilə & $\mathrm{t}$ & 4.500 & 4.227 & 0.085 & 0.138 \\
\hline kucilə & 1 & 4.500 & 5.727 & 0.753 & 0.986 \\
\hline mannilə & $\mathrm{t}$ & 3.636 & 3.500 & 0.085 & 0.138 \\
\hline mannilə & 1 & 3.636 & 6.273 & 0.753 & 0.986 \\
\hline memilə & $\mathrm{t}$ & 4.727 & 4.000 & 0.085 & 0.163 \\
\hline memilə & 1 & 4.727 & 5.955 & 0.813 & 0.986 \\
\hline mewalə & $\mathrm{t}$ & 3.273 & 3.273 & 0.073 & 0.133 \\
\hline mewalə & 1 & 3.273 & 5.455 & 0.768 & 0.986 \\
\hline putiilə & $\mathrm{t}$ & 2.727 & 3.864 & 0.085 & 0.138 \\
\hline putiilə & 1 & 2.727 & 5.455 & 0.753 & 0.986 \\
\hline piyalə & $\mathrm{t}$ & 3.318 & 3.500 & 0.073 & 0.133 \\
\hline piyalə & 1 & 3.318 & 5.455 & 0.768 & 0.986 \\
\hline
\end{tabular}

606 
SPEAKERS' KNOWLEDGE OF ALTERNATIONS

$\begin{array}{llllll}\text { s'ahilə } & \mathrm{t} & 3.409 & 3.409 & 0.085 & 0.163 \\ \text { s'ahilə } & \mathrm{l} & 3.409 & 5.636 & 0.792 & 0.986 \\ \text { ipilə } & \mathrm{t} & 4.045 & 3.455 & 0.085 & 0.163 \\ \text { ipilə } & 1 & 4.045 & 5.591 & 0.813 & 0.986\end{array}$

(B2) Inflected forms employed in backward formation test

\begin{tabular}{|c|c|c|c|c|c|}
\hline & & MEAN & MEAN & & \\
\hline & & STEM & INFLECTED & FORWARD & BACKWARD \\
\hline STIMULUS & RESPONSE & RATING & RATING & CONFIDENCE & CONFIDENCE \\
\hline kolapc'a & w & 4.100 & 3.750 & 0.000 & 0.000 \\
\hline kolapc'a & $\mathrm{p}$ & 4.100 & 5.850 & 0.916 & 0.501 \\
\hline nalupc'a & W & 4.650 & 3.750 & 0.389 & 0.278 \\
\hline nalupc'a & $\mathrm{p}$ & 4.650 & 6.150 & 0.916 & 0.426 \\
\hline nalipc'a & w & 4.750 & 4.100 & 0.389 & 0.278 \\
\hline nalipc'a & $\mathrm{p}$ & 4.750 & 5.650 & 0.916 & 0.610 \\
\hline nasupc'a & w & 4.350 & 4.500 & 0.389 & 0.278 \\
\hline nasupc'a & $\mathrm{p}$ & 4.350 & 6.650 & 0.916 & 0.426 \\
\hline nepc'a & W & 4.350 & 4.200 & 0.000 & 0.000 \\
\hline nepc'a & $\mathrm{p}$ & 4.350 & 6.300 & 0.916 & 0.512 \\
\hline nəlepc'a & W & 3.500 & 3.900 & 0.000 & 0.000 \\
\hline nəlepc'a & $\mathrm{p}$ & 3.500 & 5.700 & 0.916 & 0.512 \\
\hline nipc'a & W & 5.050 & 3.600 & 0.389 & 0.278 \\
\hline nipc'a & $\mathrm{p}$ & 5.050 & 6.050 & 0.916 & 0.610 \\
\hline mesipc'a & w & 4.800 & 4.000 & 0.389 & 0.278 \\
\hline mesipc'a & $\mathrm{p}$ & 4.800 & 6.250 & 0.916 & 0.610 \\
\hline sәрc'a & W & 5.750 & 3.600 & 0.000 & 0.000 \\
\hline səpc'a & $\mathrm{p}$ & 5.750 & 6.000 & 0.916 & 0.512 \\
\hline asapc'a & W & 4.700 & 3.750 & 0.000 & 0.000 \\
\hline asapc'a & $\mathrm{p}$ & 4.700 & 6.550 & 0.916 & 0.501 \\
\hline kamyətc'a & zero & 2.700 & 3.050 & 0.396 & 0.127 \\
\hline kamyətc'a & $\mathrm{t}$ & 2.700 & 5.350 & 0.916 & 0.421 \\
\hline kamyətc'a & s & 2.700 & 4.750 & 0.872 & 0.108 \\
\hline kamyətc'a & 1 & 2.700 & 2.800 & 0.085 & 0.163 \\
\hline kamyətc'a & $\mathrm{c}$ & 2.700 & 5.100 & 0.625 & 0.303 \\
\hline kyətc'a & zero & 4.950 & 2.850 & 0.396 & 0.127 \\
\hline kyətc'a & $\mathrm{t}$ & 4.950 & 6.050 & 0.916 & 0.421 \\
\hline kyətc'a & $\mathrm{s}$ & 4.950 & 3.850 & 0.872 & 0.108 \\
\hline kyətc'a & 1 & 4.950 & 2.750 & 0.085 & 0.163 \\
\hline kyətc'a & $\mathrm{c}$ & 4.950 & 4.250 & 0.625 & 0.303 \\
\hline kucitc'a & zero & 6.000 & 3.100 & 0.123 & 0.130 \\
\hline kucitc'a & $\mathrm{t}$ & 6.000 & 4.900 & 0.916 & 0.421 \\
\hline kucitc'a & s & 6.000 & 5.150 & 0.872 & 0.107 \\
\hline kucitc'a & 1 & 6.000 & 2.750 & 0.085 & 0.138 \\
\hline
\end{tabular}


JONGHO JUN \& ADAM ALBRIGHT

$\begin{array}{llllll}\text { kucitc'a } & \text { c } & 6.000 & 6.800 & 0.740 & 0.607 \\ \text { mannitc'a } & \text { zero } & 3.000 & 3.050 & 0.123 & 0.130 \\ \text { mannitc'a } & \text { t } & 3.000 & 4.600 & 0.916 & 0.421 \\ \text { mannitc'a } & \text { s } & 3.000 & 4.100 & 0.872 & 0.107 \\ \text { mannitc'a } & 1 & 3.000 & 3.450 & 0.085 & 0.138 \\ \text { mannitc'a } & \text { c } & 3.000 & 5.800 & 0.740 & 0.389 \\ \text { memitc'a } & \text { zero } & 4.100 & 3.000 & 0.396 & 0.145 \\ \text { memitc'a } & \text { t } & 4.100 & 5.650 & 0.916 & 0.421 \\ \text { memitc'a } & \text { s } & 4.100 & 4.950 & 0.872 & 0.108 \\ \text { memitc'a } & 1 & 4.100 & 3.250 & 0.085 & 0.163 \\ \text { memitc'a } & \text { c } & 4.100 & 5.200 & 0.625 & 0.329 \\ \text { mewatc'a } & \text { zero } & 3.600 & 2.200 & 0.000 & 0.000 \\ \text { mewatc'a } & \text { t } & 3.600 & 4.450 & 0.916 & 0.421 \\ \text { mewatc'a } & \text { s } & 3.600 & 5.550 & 0.872 & 0.113 \\ \text { mewatc'a } & 1 & 3.600 & 2.850 & 0.073 & 0.133 \\ \text { mewatc'a } & \text { c } & 3.600 & 5.000 & 0.625 & 0.303 \\ \text { putiitc'a } & \text { zero } & 3.050 & 4.000 & 0.123 & 0.130 \\ \text { putiitc'a } & \text { t } & 3.050 & 4.800 & 0.916 & 0.421 \\ \text { putiitc'a } & \text { s } & 3.050 & 4.900 & 0.872 & 0.107 \\ \text { putiitc'a } & 1 & 3.050 & 3.300 & 0.085 & 0.138 \\ \text { putiitc'a } & \text { c } & 3.050 & 5.400 & 0.740 & 0.389 \\ \text { piyatc'a } & \text { zero } & 3.800 & 2.550 & 0.000 & 0.000 \\ \text { piyatc'a } & \text { t } & 3.800 & 4.850 & 0.916 & 0.421 \\ \text { piyatc'a } & \text { s } & 3.800 & 5.150 & 0.872 & 0.113 \\ \text { piyatc'a } & 1 & 3.800 & 3.000 & 0.073 & 0.133 \\ \text { piyatc'a } & \mathrm{c} & 3.800 & 4.150 & 0.625 & 0.303 \\ \text { s'ahitc'a } & \text { zero } & 3.150 & 3.350 & 0.396 & 0.145 \\ \text { s'ahitc'a } & \text { t } & 3.150 & 4.850 & 0.916 & 0.421 \\ \text { s'ahitc'a } & \text { s } & 3.150 & 4.950 & 0.872 & 0.108 \\ \text { s'ahitc'a } & 1 & 3.150 & 2.900 & 0.085 & 0.163 \\ \text { s'ahitc'a } & \text { c } & 3.150 & 4.150 & 0.625 & 0.329 \\ \text { ipitc'a } & \text { zero } & 3.850 & 3.900 & 0.396 & 0.145 \\ \text { ipitc'a } & \text { t } & 3.850 & 4.650 & 0.916 & 0.421 \\ \text { ipitc'a } & \text { s } & 3.850 & 3.900 & 0.872 & 0.108 \\ \text { ipitc'a } & 1 & 3.850 & 2.650 & 0.085 & 0.163 \\ \text { ipitc'a } & \text { c } & 3.850 & 4.500 & 0.625 & 0.329\end{array}$




\section{REFERENCES}

Albright, Adam. 2002a. The identification of bases in morphological paradigms. Ph.D. dissertation, University of California, Los Angeles.

Albright, Adam. 2002b. Islands of reliability for regular morphology: Evidence from Italian. Language 78.4, 684-709.

Albright, Adam. 2005. The morphological basis of paradigm leveling. In Laura Downing, Tracy Alan Hall \& Renate Raffelsiefen (eds.), Paradigms in phonological theory, 17-43. Oxford: Oxford University Press.

Albright, Adam. 2008. Explaining universal tendencies and language particulars in analogical change. In Jeff Good (ed.), Language universals and language change, 144-181. Oxford: Oxford University Press.

Albright, Adam, Argelia Andrade \& Bruce Hayes. 2001. Segmental environments of Spanish diphthongization. In Adam Albright \& Taehong Cho (eds.), Papers in phonology 5 (UCLA Working Papers in Linguistics 7), 117-151. Los Angeles, CA: University of California, Los Angeles.

Albright, Adam \& Bruce Hayes. 2002. Modeling English past tense intuitions with minimal generalization. In Mike Maxwell (ed.), Proceedings of the 6th Meeting of the ACL Special Interest Group in Computational Phonology, 58-69. Philadelphia, PA: The Association for Computational Linguistics.

Albright, Adam \& Bruce Hayes. 2003. Rules vs. analogy in English past tenses: A computational/experimental study. Cognition 90, 119-161.

Albright, Adam \& Yoonjung Kang. 2009. Predicting innovative variants in Korean verb paradigms. In The Linguistics Society of Korea (ed.), Current issues in unity and diversity of languages: Collection of papers selected from the 18th International Congress of Linguists (CIL 18), 893-913. Seoul: Dongam.

Bates, Douglas, Martin Maechler \& Ben Bolker. 2011. lme4: Linear mixed-effects models using S4 classes. R package version 0.999375-39. http://CRAN.R-project.org/package=lme4.

Becker, Michael. 2009. Phonological trends in the lexicon: The role of constraints. Ph.D. dissertation, University of Massachusetts, Amherst.

Becker, Michael, Nihan Ketrez \& Andrew Nevins. 2011. The surfeit of the stimulus: Grammatical biases filter lexical statistics in Turkish voicing deneutralization. Language 87.1, 84-125.

Benua, Laura. 1997. Transderivational identity: Phonological relations between words. Ph.D. dissertation, University of Massachusetts, Amherst. [Published by Garland: Outstanding Dissertations in Linguistics]

Berko, Jean. 1958. The child's learning of English morphology. Word 14, 150-177.

Bybee, Joan. 2001. Phonology and language use. Cambridge: Cambridge University Press.

Choi, Myungok. 1985. Phonological phenomena of irregular verbs with focus on p-, s-, t- irregulars [pyenchik tongsauy umwunhyensangey tayhaye - p-, s-, t-pyenchiktongsalul cwungsimulo]. kwukehak 14, 149-188. [In Korean]

Coetzee, Andries W. 2008. Grammaticality and ungrammaticality in phonology. Language 84.2, 218-257.

Coetzee, Andries W. 2009. Learning lexical indexation. Phonology 26, 109-145.

Do, Young Ah. 2013. Biased learning of phonological alternations. Ph.D. dissertation, MIT.

Ernestus, Mirjam \& R. Harald Baayen. 2003. Predicting the unpredictable: Interpreting neutralized segments in Dutch. Language 79, 5-38.

Han, Youngkyun. 1985. Phonological change and reconstruction of the lexicon [umwunpyenhwawa ehwipwuuy caykwucohwa]. kwanakemunyenku 10, 375-402. [In Korean]

Hayes, Bruce. 1998. On the richness of paradigms, and the insufficiency of underlying representations in accounting for them. Handout for a talk, Stanford University, 2 April 21998.

Hayes, Bruce \& Zsuzsa Cziráky Londe. 2006. Stochastic phonological knowledge: The case of Hungarian vowel harmony. Phonology 23, 59-104.

Hayes, Bruce \& James White. 2013. Phonological naturalness and phonotactic learning. Linguistic Inquiry 44, 45-75.

Hayes, Bruce, Kie Zuraw, Peter Siptar \& Zsuzsa [Cziráky] Londe. 2009. Natural and unnatural constraints in Hungarian vowel harmony. Language 85.4, 822-863.

Jun, Jongho. 2010. Stem-final obstruent variation in Korean. Journal of East Asian Linguistics 19.2, $137-179$.

Jun, Jongho. 2015. Korean n-insertion: A mismatch between data and learning. Phonology 32.3, $417-458$. 
Jun, Jongho \& Jeehyun Lee. 2007. Multiple stem-final variants in Korean native nouns and loanwords. Eoneohag 47, 159-187.

Kang, Beom-mo \& Hung-gyu Kim. 2004. Frequency analysis of Korean morpheme and word usuage 2 [hankwuke hyengtayso mich ehwi sayong pintouy pwunsek], vol. 2. Seoul: Institute of Korean Culture, Korea University, Seoul. [In Korean]

Kang, Yoonjung. 2003. Sound changes affecting noun-final coronal obstruents in Korean. In William McClure (ed.), Japanese/Korean linguistics, vol. 12, 128-139. Stanford, CA: CSLI Publications.

Kang, Yoonjung. 2006. Neutralizations and variations in Korean verbal paradigms. In Susumu Kuno, Ik-Hwan Lee, John Whitman, Joan Maling, Young-Se Kang, Peter Sells \& Hyang-Sook Sohn (eds.), Harvard Studies in Korean Linguistics XI, 183-196. Korea: Hanshin.

Kenstowicz, Michael. 1995. Cyclic vs. non-cyclic constraint evaluation. Phonology 12, 397-436.

Kenstowicz, Michael. 1996. Base-identity and uniform exponence: Alternatives to cyclicity. In Jacques Durand \& Bernard Laks (eds.), Current trends in phonology: Models and methods, 363-393. Paris \& Salford: University of Salford Publications.

Kenstowicz, Michael \& Charles Kisseberth. 1977. Topics in phonological theory. New York: Academic Press.

Kim, Chagyun. 1971. A study of irregular verbs [pyenchik yongen yenkwu]. Hangeul 147, 83-118. [In Korean]

Kim, Chin-Wu. 1971. Regularity of the so-called irregular verbs in Korean [sowi pyenkyek yongenuy pipyenkyeksengey kwanhaye]. Hankwuk Enemunhak 8 \& 9 (combined issue), 1-12. [In Korean]

Kim, Jongkyoo. 2000. Quantity-sensitivity and feature-sensitivity of vowels: A constraint-based approach to Korean vowel phonology. Ph.D. dissertation, Indiana University.

Kim, Seongkyu. 1988. Synchronic description of non-automatic alternation [picatongcek kyocheyuy kongsicek kiswul]. Kwanakemunyenku 13, 25-44. Seoul National University, Department of Korean Language \& Literature. [In Korean]

Kim-Renaud, Young-Key. 1986. Studies in Korean linguistics. Seoul: Hanshin.

Ko, Kwang-Mo. 1989. Explaining the noun-final change $t>s$ in Korean [cheyen kkuthuy pyenhwa $t$ $>\mathrm{s}$ ey tayhan saylowun haysek]. Eoneohag 11, 3-22. [In Korean]

Kuryłowicz, Jerzy. 1947. The nature of the so-called analogical processes. Diachronica 12.1, 113-145.

Kwuklip kwuke yenkwuwen [National Institute of the Korean Language] (ed.). 1999. Standard Korean dictionary [pyocwun kwuke taysacen]. Seoul: Doosan Dong-A. Available at http://stdweb2.korean. go.kr. [In Korean]

Lee, Byung-Gun. 1976. Generative phonology of modern Korean [hyentay hankwukeuy sayngsengumwunlon]. Seoul: Ilcisa. [In Korean]

Lee, Sang-Oak. 2008. A study on sound change of Korean verbs and adjectives in Chosun dynasty [cosensitay hankuke yongenuy umpyenhwa yenku]. Seoul: Pakijeong. [In Korean]

Mańczak, Witold. 1958. Tendences générales des changements analogiques. Lingua 7, 298-325 \& $387-420$

Mikheev, Andrei. 1997. Automatic rule induction for unknown-word guessing. Computational Linguistics 23, 405-423.

Mok, Jung-Soo. 2003. Korean grammar [hankuke munpeplon]. Seoul: Worin. [In Korean]

Moreton, Elliott. 2008. Analytic bias and phonological typology. Phonology 25, 83-128.

Pater, Joe. 2000. Nonuniformity in English stress: The role of ranked and lexically specific constraints. Phonology 17, 237-274.

Pater, Joe, Robert Staubs, Karen Jesney \& Brian Smith. 2012. Learning probabilities over underlying representations. Proceedings of the Twelfth Meeting of ACL-SIGMORPHON: Computational Research in Phonetics, Phonology, and Morphology, 62-71. Montreal: The Association for Computational Linguistics.

Pinker, Steven. 1999. Words and rules: The ingredients of language. New York: Harper Collins.

Pinker, Steven \& Alan S. Prince. 1988. On language and connectionism: Analysis of a parallel distributed processing model of language acquisition. Cognition 28, 73-193.

R Development Core Team. 2014. R: A language and environment for statistical computing. Vienna: R Foundation for Statistical Computing. Available at http://www.rproject.org.

Sohn, Ho-Min. 1999. The Korean language (Cambridge Language Surveys). Cambridge: Cambridge University Press.

Steriade, Donca. 2000. Paradigm uniformity and the phonetics-phonology boundary. In Michael B. Broe \& Janet B. Pierrehumbert (eds.), Papers in Laboratory Phonology V: Acquisition and the lexicon, 313-334. Cambridge: Cambridge University Press. 


\section{SPEAKERS' KNOWLEDGE OF ALTERNATIONS}

Wilson, Colin. 2006. Learning phonology with substantive bias: An experimental and computational study of velar palatalization. Cognitive Science 30, 945-982.

Zuraw, Kie. 2000. Patterned exceptions in phonology. Ph.D. dissertation, University of California, Los Angeles.

Zuraw, Kie. 2002. Aggressive reduplication. Phonology 19.3, 395-539.

Zuraw, Kie. 2007. The role of phonetic knowledge in phonological patterning: Corpus and survey evidence from Tagalog infixation. Language 83, 277-316.

Zuraw, Kie. 2010. A model of lexical variation and the grammar with application to Tagalog nasal substitution. Natural Language \& Linguistic Theory 28, 417-472.

Authors'addresses: (Jun)

Linguistics Department, Seoul National University,

1 Gwanak-ro, Gwanak-gu, Seoul, 08826, South Korea jongho@snu.ac.kr

(Albright)

MIT Linguistics and Philosophy, 77 Massachusetts Avenue,

32-D808 Cambridge, MA 02139, USA

albright@mit.edu 